IZA DP No. 5779

Estimating Heterogeneous Take-up and

Crowd-Out Responses to Marginal and Non-Marginal Medicaid Expansions

John C. Ham

I. Serkan Ozbeklik

Lara Shore-Sheppard

June 2011 


\title{
Estimating Heterogeneous Take-up and Crowd-Out Responses to Marginal and Non-Marginal Medicaid Expansions
}

\author{
John C. Ham \\ University of Maryland, \\ IRP (Madison) and IZA \\ I. Serkan Ozbeklik \\ Claremont McKenna College \\ Lara Shore-Sheppard \\ Williams College and NBER \\ Discussion Paper No. 5779 \\ June 2011 \\ IZA \\ P.O. Box 7240 \\ 53072 Bonn \\ Germany \\ Phone: +49-228-3894-0 \\ Fax: +49-228-3894-180 \\ E-mail: iza@iza.org
}

\begin{abstract}
Any opinions expressed here are those of the author(s) and not those of IZA. Research published in this series may include views on policy, but the institute itself takes no institutional policy positions.

The Institute for the Study of Labor (IZA) in Bonn is a local and virtual international research center and a place of communication between science, politics and business. IZA is an independent nonprofit organization supported by Deutsche Post Foundation. The center is associated with the University of Bonn and offers a stimulating research environment through its international network, workshops and conferences, data service, project support, research visits and doctoral program. IZA engages in (i) original and internationally competitive research in all fields of labor economics, (ii) development of policy concepts, and (iii) dissemination of research results and concepts to the interested public.
\end{abstract}

IZA Discussion Papers often represent preliminary work and are circulated to encourage discussion. Citation of such a paper should account for its provisional character. A revised version may be available directly from the author. 


\section{ABSTRACT \\ Estimating Heterogeneous Take-up and Crowd-Out Responses to Marginal and Non-Marginal Medicaid Expansions ${ }^{\star}$}

We use a linear probability model with interactions and a switching probit model (SPM) to estimate heterogeneous effects of Medicaid expansions on Medicaid take-up, private insurance coverage and crowd-out. Specifically, we estimate: i) LATEs; ii) ATETs for the currently eligible; and iii) ATETs for those made eligible by a non-marginal (counterfactual) expansion in Medicaid eligibility. Both estimation methods can control for observable differences across individuals, while SPM can also control for unobservable differences. For Medicaid take-up and private insurance coverage, the effects are precisely estimated and differ dramatically across demographic groups, but this is less true for the crowd-out estimates.

JEL Classification: I18, C21

Keywords: Medicaid expansions, take-up, crowd-out, treatment effects, switching probit model, linear probability model with interactions, counterfactual policy analysis

Corresponding author:

John C. Ham

Department of Economics

University of Maryland

3105 Tydings Hall

College Park, MD 20742

USA

E-mail: ham@econ.umd.edu

\footnotetext{
* We are grateful to Steven Cosslett, Curtis Eberwein, Ingmar Prucha, Geert Ridder, Sergio Urzúa, Frank Vella and seminar participants at Ohio State University and Georgetown University for comments. This research has been supported by grants from the National Science Foundation (SES0136928 and SES-0627968) and the National Institute of Child Health and Human Development (R01 HD39369-01A1). Any opinions, findings, and conclusions or recommendations in this paper are those of the authors and do not necessarily reflect the views of the National Science Foundation or National Institute of Child Health and Human Development.
} 


\section{Introduction}

In recent years, eligibility for public health insurance has expanded substantially, leading to a burgeoning of research on the implications of such expansions for public insurance participation, private insurance crowd-out, and overall levels of health insurance coverage. A common approach to these questions is to estimate a linear probability model of participation (or private or overall insurance coverage) where a dummy variable for eligibility for the program is an endogenous explanatory variable and exogenous variation in eligibility is used to generate an instrumental variable (see Cutler and Gruber (1996), Currie and Gruber (1996a, 1996b), LoSasso and Buchmueller (2004), Hudson, Selden, and Banthin (2005), Ham and Shore-Sheppard (2005), and Shore-Sheppard (2008), among others). This model permits the estimation of Local Average Treatment Effects (LATEs) on take-up and crowd-out-the average effect of eligibility on insurance coverage among individuals who are responsive to small changes in the instrument used for identification - the marginally eligible. This approach, while quite useful, has three drawbacks. First, the composition of the group to which the LATE estimates apply is generally unobserved by the researcher. Second, the estimated LATEs provide no information about which sub-groups have low or high responses to marginal or non-marginal (large, counterfactual) changes in eligibility. As we demonstrate below, observable groups vary dramatically in their take-up response to marginal or non-marginal Medicaid expansions, and it would be very helpful for policy makers to know how responses differ when designing outreach programs. Third, this model may lead to misleading predictions of the effects of non-marginal expansions if the individuals made eligible by a non-marginal expansion of Medicaid income limits across children's age groups and states have different observed or unobserved characteristics than those for whom the LATEs are estimated. 
Recently, the empirical program evaluation literature has seen a number of papers that explicitly estimate heterogeneous treatment effects for different groups, and thus have the potential to be much more informative for policy analysis. The majority of these effects have been estimated within the education and training literature (see, e.g., Aakvik, Heckman, and Vytlacil (2005—hereafter AHV), Blundell, Dearden, and Sianesi (2005), Card and Payne (2003), Heckman, Smith, and Clemens (1997), and Moffitt (2007)), although there are other applications (see, e.g., Angrist (2004) for treatment effect heterogeneity in the effects of childbearing on marital dissolutions, poverty status, and welfare participation). One popular approach in this literature is to estimate a linear probability model where the treatment dummy variable is interacted with demographic variables to estimate LATEs for different demographic groups; in what follows we refer to this model as a linear probability model with interactions (LPMI). Another approach is to use a switching probit model (SPM) to predict the effect of changing treatment on the basis of observables and unobservables. ${ }^{1}$

In this paper we use these two approaches to go beyond the existing studies on Medicaid expansions that focus on estimating a single LATE in models of take-up and crowd-out (defined as the change in the probability of private coverage due to a change in eligibility status). Using data from the Survey of Income and Program Participation (SIPP), we provide LATE estimates for marginal Medicaid expansions for different demographic groups. We also estimate take-up, participation and crowd-out responses to non-marginal (counterfactual) Medicaid expansions,

\footnotetext{
${ }^{1}$ The first approach is used by Blundell, Dearden, and Sianesi (2005) and Card and Payne (2003) while the second is used by AHV. The approach introduced in Moffitt (2007) can be considered a combination of the two, since he allows treatment effects to depend on both observables and unobservables that are correlated with the error in the outcome of interest within a random coefficients framework. Heckman, Smith, and Clemens (1997) use propensity score matching while allowing for treatment heterogeneity, while Angrist (2004) uses an IV framework to show the relationship between LATEs and average treatment effects under certain assumptions.
} 
parameters that are very useful for policymakers contemplating further expansions of program eligibility.

In estimating responses to non-marginal Medicaid expansions we extend the program evaluation literature in several directions. First, we approximate the responses to non-marginal Medicaid changes for different demographic groups using the LPMI. We describe this approach as an approximation since it captures observable, but not unobservable, differences between those made eligible by a marginal Medicaid expansion and a non-marginal Medicaid expansion. Second, we simplify the existing approach to estimating the responses to non-marginal changes in eligibility that uses a SPM; our simplification arises from the fact that Medicaid eligibility is based on observable criteria. $^{2}$ We then use this simplification to estimate the responses to nonmarginal Medicaid changes across different demographic groups. This method is able to account for both observable and unobservable differences within a demographic group between those made eligible by a marginal Medicaid expansion and those made eligible by a non-marginal Medicaid expansion. Finally, we show how we can use existing average Medicaid take-up rates in the data to perform an informal investigation of how well each of these approaches is likely to do in capturing the responses to non-marginal Medicaid expansions.

The LATE estimates we obtain differ widely across different demographic groups, suggesting that they will indeed be useful to policy makers, particularly those concerned with outreach Furthermore, our findings using both LPMI and SPM approaches indicate that there is substantial heterogeneity across different demographic groups in their responses to non-marginal (counterfactual) Medicaid expansions, and that the estimated take-up propensity for the average eligible child is substantially larger than the take-up propensity for a child made eligible by a

\footnotetext{
${ }^{2}$ These extensions can be used to evaluate the effects of non-marginal changes in other programs as long as program eligibility is based on observable factors.
} 
counterfactual Medicaid expansion. Finally, we find that the SPM does a much better job of fitting current Medicaid average take-up rates and private insurance coverage rates among those eligible across demographic groups in the actual data. Since we develop versions of both approaches that can be estimated by standard Stata programs, the SPM approach appears more useful for researchers.

The paper proceeds as follows. In the next section we discuss the Medicaid program and some previous studies that have used a two-equation linear probability model to estimate the insurance responses to Medicaid expansions. In Section 3, we outline this standard approach to public health insurance take-up and private insurance crowd-out. We then describe our use of the LPMI and SPM to estimate a range of heterogeneous treatment/policy effects, and discuss our data from the SIPP briefly in Section 4. In Section 5 we provide our estimates of LATEs by demographic group using the LPMI. We then use both the LPMI and SPM to estimate heterogeneous effects for non-marginal (counterfactual) expansions in the Medicaid income limits. Section 6 concludes the paper.

\section{Medicaid Expansions and Previous Literature}

Medicaid was first established as a public health insurance program for welfare recipients and low-income aged and disabled individuals. This focus largely remained until the late 1980s, when expansions in eligibility first permitted, and then required, states to cover pregnant women and children with family incomes that made them ineligible for cash welfare. Following the federally mandated eligibility expansions of 1989 and 1990, states were required to cover children age 6 or younger with family incomes up to 133\% of the poverty line, and children born after September 30, 1983 with family incomes up to 100\% of the poverty line. States were also given the option to increase their eligibility thresholds up to $185 \%$ of the poverty line. As these 
eligibility limits were far more generous than the eligibility limits applying to cash welfare (at the time, Aid to Families with Dependent Children, or AFDC), the link between Medicaid eligibility and AFDC eligibility greatly diminished for young, low-income children. By 1996, of the approximately $30 \%$ of children age 19 and younger who were eligible for Medicaid, only about half came from typically welfare-enrolled families (Selden, Banthin, and Cohen 1998). While families who enrolled in cash welfare programs were also automatically enrolled in Medicaid, children newly eligible for the program were not. Consequently the establishment of a new route to Medicaid eligibility raised two important policy questions. First, to what extent did expanded eligibility lead to increased health insurance coverage for the targeted population of children? Second, did expanded eligibility lead to "crowding out" of private health insurance by public insurance availability (and if so to what extent), since newly eligible children were less poor than previously eligible children and hence more likely to have access to private insurance?

There has been a substantial amount of research on these initial Medicaid expansions, and a non-exhaustive list includes Currie and Gruber (1996a, 1996b), Cutler and Gruber (1996), Dubay and Kenney (1996), Thorpe and Florence (1998), Yazici and Kaestner (1999), ShoreSheppard (2000), Blumberg, Dubay, and Norton (2000), Card and Shore-Sheppard (2004), Ham and Shore-Sheppard (2005), and Shore-Sheppard (2008). Further, there is also research on the related question of how the further public health insurance expansions of the State Children's Health Insurance Program (SCHIP) affected coverage and crowd-out (see LoSasso and Buchmueller (2004), Hudson, Selden, and Banthin (2005), and Gruber and Simon (2008)). The above papers have provided estimates of a variety of behavioral parameters related to the responsiveness of children's insurance coverage to expanded eligibility. The most common approach used for estimating effects of expanded eligibility is an instrumental variable linear 
probability model (LPM) that we describe in more detail below. This approach produces LATE estimates of take-up and private coverage responses for an unknown (to the researcher) group of individuals who are responsive to small changes in the instrument used for identification. Of course, the LATE estimates are not the same as the average take-up rate or private coverage loss among all eligible children (that is, including those children who were eligible prior to the expansion being studied). Moreover, they generally do not reflect the change that would occur in take-up or private coverage from a medium-sized or large change in eligibility. ${ }^{3}$ Definitions of "crowd-out"-loosely, the effect of public insurance availability on the propensity to have private coverage-are particularly diverse in the literature. For expositional purposes we will focus on one definition, but our methodology is easily generalized to other definitions. In this paper, we estimate a host of additional effects for take-up and crowd-out.

Since our aim in this paper is to extend previous results rather than summarizing the literature, here we focus on two of the studies that use this now standard approach. An important study using this approach is the seminal paper of Cutler and Gruber (1996-CG hereafter). CG use a linear probability model (LPM) and data on children from the March Current Population Survey (CPS) from 1988 to 1993 to estimate the effect of imputed Medicaid eligibility on insurance status, controlling for demographics and state and year effects. They use an IV version of the LPM (discussed briefly in Section 3.2 below) since eligibility is likely to be endogenous. This potential endogeneity arises for several reasons. First, unobservable factors affecting eligibility are likely to be correlated with unobservable factors driving family characteristics that determine eligibility. Second, eligibility may serve as a proxy for family income if income, which is also likely to be endogenous, is not included as an independent variable. Finally, parental wages, which in turn determine eligibility, are likely to be correlated with fringe benefits

\footnotetext{
${ }^{3}$ These distinctions have often been missed in the literature.
} 
(including private health insurance) of the parent. Since these benefits are unobserved, they are part of the error term, thus providing an additional factor necessitating treating eligibility as endogenous. To address the endogeneity of the eligibility variable, CG suggest an instrument (which we denote FRACELIG) that is the fraction of a random sample of 300 children of each age imputed to be eligible according to the rules in each state in each year. This instrument, which is essentially an index of the expansiveness of Medicaid eligibility for each age group in each state and year, is correlated with individual eligibility for Medicaid but not otherwise correlated with the demand for insurance, assuming that changes in a state's Medicaid provisions are not correlated with changes in the state's availability of private insurance, which are unobservable to the researcher. ${ }^{4}$ CG estimate LATEs for take-up and crowd-out of $23.5 \%$ and $7 \%$ respectively. As noted above these IV estimates are for those children whose eligibility is sensitive to a small change in FRACELIG.

Ham and Shore-Sheppard (2005-HS hereafter) use data from the SIPP covering the period from October 1985 to August 1995 to replicate CG's analysis. As with CG, they estimate LATEs, and thus the results of the two papers are comparable. HS find smaller LATEs for takeup rate and crowd-out than CG. They attribute some of the differences between their results and CG's to different samples and recall periods in SIPP and the CPS. HS also modify the CG instrument by using all sample observations of children of a given age in a SIPP wave except for those from the state for which the instrument is being calculated. Since this instrument is created using a larger sample, it is theoretically superior to the version using a random sample, but in

\footnotetext{
${ }^{4}$ One attractive feature of this approach is that FRACELIG is an extremely strong instrument. This is very helpful since we obtain precisely estimated marginal treatment effects for many demographic groups using FRACELIG times the demographic variables as instruments; this is not always the case in estimating such a model, see, e.g. Blundell, Dearden, and Sianesi (2005).
} 
practice its use makes very little difference to the results. We use the data and instrument of HS in our estimation.

\section{Estimating the Effects of Marginal and Non-Marginal (Counterfactual) Medicaid Expansions Across Demographic Groups}

\subsection{Estimating LATEs for Medicaid Expansions}

Following the above literature, we first explicitly discuss using simultaneous equation LPMs. The LPM for participation in a public insurance program is given by

$$
\operatorname{pub}_{\mathrm{i}}=X_{i} \beta_{1}+\gamma_{1} \text { elig }_{i}+u_{1 i} \text {, }
$$

where $X_{i}$ is a vector of demographic variables for child $i$, elig $g_{i}$ is a dummy variable coded one if the child is eligible for public insurance and zero otherwise, $u_{1 i}$ is an error term, and $p u b_{i}=1$ if child $i$ participates in a public insurance program, otherwise $p u b_{i}=0$. The LPM for private insurance coverage is given by

$$
\operatorname{priv}_{\mathrm{i}}=X_{i} \beta_{2}+\gamma_{2} \text { elig }_{i}+u_{2 i}
$$

where $\operatorname{priv}_{i}=1$ if child $i$ has private insurance coverage and $\operatorname{priv}_{i}=0$ otherwise. For ease of exposition, think of $X_{i}$ as a fully interacted vector of demographic variables that equal one for a given demographic cell and zero otherwise. The LPM determining public insurance eligibility is

$\operatorname{elig}_{i}=Z_{i} \delta+e_{i}$

where $Z_{i}=\left(X_{i}, F R A C E L I G_{i}\right)$, and $e_{i}$ is an error term. From the discussion in CG, it is clear that they interpret the coefficients $\gamma_{1}$ and $\gamma_{2}$ as LATEs, i.e. treatment effects for individuals whose

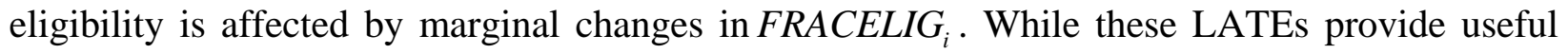
summary statistics, they will be less useful for predicting the effect of an eligibility change that 
affects children with different characteristics, estimating average take-up rates among the currently eligible or estimating take-up among those made eligible by a non-marginal expansion.

To address these limitations, we first consider a model that consists of a LPMI for participation in public insurance and a LPMI for participation in private insurance. Specifically, we interact $e \operatorname{lig}_{i}$ with each of the K elements of $X_{i}$ to obtain ${ }^{5}$

$$
p u b_{\mathrm{i}}=X_{i} \beta_{1}+\left(e \operatorname{elg}_{i} X_{i}\right) \theta_{1}+u_{1 i}=\sum_{k=1}^{K} X_{i k}\left(\beta_{1 k}+\theta_{1 k} e l i g_{i}\right)+u_{1 i}
$$

We follow the same approach to obtain the following LPMI for private insurance participation

$$
\operatorname{priv}_{\mathrm{i}}=X_{i} \beta_{2}+\left(\text { elig }_{i} X_{i}\right) \theta_{2}+u_{2 i}=\sum_{k=1}^{K} X_{i k}\left(\beta_{2 k}+\theta_{2 k} e l i g_{i}\right)+u_{2 i} \text {. }
$$

The natural vector of excluded instruments in (3a) and (3b) for the $K$ by 1 vector of endogenous variables $\left(\operatorname{elig}_{i} X_{i}\right)$ is the $\mathrm{K}$ by 1 vector $\left(F R A C E L I G_{i} * X_{i}\right)$. This model therefore estimates a LATE for each demographic cell in the data, and we use $\hat{\theta}_{1 j}\left(\hat{\theta}_{2 j}\right)$ to estimate the effect of eligibility on the Medicaid (private insurance) participation for a given group of individuals with characteristics $X_{j} \cdot{ }^{6}$

\subsection{Estimating Take-Up and Coverage Effects Using the Linear Probability Model with Interactions}

As noted above, standard LATE estimates show the response for an unknown group of individuals, and our LPMI estimates identify marginal responses for unknown individuals within each demographic group. However, for a Medicaid expansion we can identify the marginal

\footnotetext{
${ }^{5}$ An alternative approach would be to use $\left(X_{i}^{*}\left(Z_{i} * \hat{\delta}\right)\right)$ as a vector of instruments, where $\hat{\delta}$ is estimated by (2) -see Amemiya (1985). However, for comparability with other studies, we follow the procedure in the text.

${ }^{6}$ In what follows $\hat{\theta}_{1 j}$ is our estimate of $\theta_{1 j}$, and we define other estimated parameters in an analogous way.
} 
group whose behavior is reflected by the IV coefficients, i.e. those whose eligibility in the group is affected by a small change in FRACELIG. (Note we are using small changes in FRACELIG as representing a marginal Medicaid expansion.) A natural way of identifying this group is to see who becomes newly eligible in the data for a small change in the Medicaid limits that would correspond to a small change in FRACELIG. For example, one could look at which children become eligible when the income limits relevant to their age and state go from $1 \%$ below their current value to $1 \%$ over their current value.

More importantly, we can use a similar approach to identify the group of children made eligible by a non-marginal expansion of Medicaid, such as a $10 \%$ increase in the income limits for each age group in each state-again we can observe which children in the data become newly eligible from this change. ${ }^{7}$ Of course, those made eligible by a marginal change and those made eligible by a non-marginal change will differ in terms of observable and unobservable characteristics. Given knowledge of who is made eligible by the non-marginal Medicaid expansion, our use of the LPMI allows us to take into account the observable differences, but not unobservable differences, between these newly eligible and the marginally eligible to estimate take up by the newly eligible, as we show below. This approach is not currently available in the literature.

We first consider average take-up rate and begin by identifying who is eligible under the current income limits. We estimate the average take-up rate among the eligible-the Average Treatment Effect on the Treated (ATET)—using

$$
\operatorname{ATRE} E^{l p m}=\sum_{\text {eligi }}\left[X_{i} \hat{\beta}_{1}+X_{i} \hat{\theta}_{1}\right] / N_{e},
$$

\footnotetext{
${ }^{7}$ We abstract from the possibility that individuals above the new cutoffs may reduce their income so that their children will qualify for Medicaid.
} 
where $\hat{\beta}_{1}$ and $\hat{\theta}_{1}$ are parameter estimates from (3a) and $N_{e}$ is the number of eligible children. Here we use $\hat{\theta}_{1}$ to impute take-up for all observably eligible individual, noting that this is an approximation since it only takes into account observable differences between the marginally eligible (used to estimate $\hat{\theta}_{1}$ ) and all eligible individuals. We denote the set of children eligible for Medicaid in demographic group $j$ by $G_{j}$. Then we approximate the average take-up rate among the eligible for group $j$ as

$$
\operatorname{ATRE}_{j}^{l p m}=\sum_{i \in G_{j}}\left[X_{i} \hat{\beta}_{1}+X_{i} \hat{\theta}_{1}\right] / N_{e j},
$$

where $N_{e j}$ is the number of eligible children in group $j$.(Although our emphasis in the empirical work is estimating all effects for different demographic groups, to save space in what follows we omit the effects for different groups since it is straightforward to define them.)

Furthermore, take-up for a randomly chosen person, i.e. the average treatment effect (ATE hereafter), can be approximated by

$$
A T R^{l p m}=\sum_{i=1}^{N}\left[X_{i} \hat{\beta}_{1}+X_{i} \hat{\theta}_{1}\right] / N
$$

where $N$ is the sample size.

We can measure the average private insurance coverage rate among those who are eligible for Medicaid as

$$
\operatorname{PITE}^{l p m}=\sum_{\text {eligi } i=1}\left[X_{i} \hat{\beta}_{2}+X_{i} \hat{\theta}_{2}\right] / N_{e},
$$

and use an analogous expression for the private insurance coverage rate among the eligible in demographic group $j$. We calculate the counterfactual average private insurance coverage rate among those eligible, if they were not eligible, as 
$\operatorname{PITNE}^{l p m}=\sum_{\text {eligi }}\left[X_{i} \hat{\beta}_{2}\right] / N_{e}$

where $\hat{\beta}_{2}$ and $\hat{\theta}_{2}$ are the estimated values of $\beta_{2}$ and $\theta_{2}$ respectively from (3b). We define crowdout for a child as the probability that the child has private insurance when not eligible for Medicaid minus the probability the child has private insurance when eligible for Medicaid. Thus, we measure average crowd-out among all those eligible as

$$
\operatorname{COE}^{l p m}=\operatorname{PITNE}^{l p m}-\operatorname{PITE}^{l p m}=-\sum_{\text {eligi } i}\left[X_{i} \hat{\theta}_{2}\right] / N_{e} .
$$

Since the measures in (4a)-(4f) are linear functions of regression coefficients, we can calculate their standard errors using preprogrammed commands in Stata. It is important to note that we can only calculate these effects with the LPMI because we can identify who is eligible, and thus our approach can be used to estimate take-up in any other programs where eligibility is determined based on observable characteristics. ${ }^{8}$ To the best of our knowledge, our paper is the first to approximate these effects using the LPMI.

Perhaps more importantly, we also can estimate the take-up response and crowd-out effect of a non-marginal Medicaid expansion across different demographic groups using the estimates from the LPMI. To calculate the effect of a non-marginal expansion, we first increase the income limits by an appropriate amount, and then determine which children would become newly eligible under the expansion, denoting this group as New. ${ }^{9}$ (In what follows we refer to this group as the newly eligible.) Then a natural means of approximating take-up among the newly eligible is

\footnotetext{
${ }^{8}$ Details on this calculation and our Stata programs to implement all approaches used in the paper are given in our Online Appendix A.

${ }^{9}$ Below we consider a 10 percent increase in the 1995 income limits for all age groups in all states.
} 
$T N E W^{l p m}=\sum_{i \in N e w}\left[X_{i} \hat{\beta}_{1}+X_{i} \hat{\theta}_{1}\right] / N_{N e w}$

where $N_{\text {New }}$ is the number of newly eligible.

We estimate private insurance coverage among the newly eligible using

$$
\text { PITENEW } W^{l p m}=\sum_{i \in N e w}\left[X_{i} \hat{\beta}_{2}+X_{i} \hat{\theta}_{2}\right] / N_{N e w} .
$$

In the absence of the non-marginal expansion, these individuals would have had private insurance coverage given by

$$
\text { PITNENEW } W^{l p m}=\sum_{i \in N e w}\left[X_{i} \hat{\beta}_{2}\right] / N_{N e w} \text {. }
$$

We can estimate the crowd-out effect among all the newly eligible as

$$
C N E W^{l p m}=-\sum_{i \in N e w}\left[X_{i} \hat{\theta}_{2}\right] / N_{N e w}
$$

We should mention, however, one further caveat to our approach, in addition to the fact that we cannot control for unobservable differences between the newly eligible and those made eligible by a non-marginal Medicaid eligibility expansion. In many datasets, including the one we use below, there may not be enough observations to include dummy variables for each demographic cell. Instead, we have to settle for controlling for the effect of demographic variables without fully interacting them. Thus, we will only be able to control approximately for differences in observables across individuals. However, both of these problems are resolved when we use the switching probit model in the next section.

\subsection{Estimating the Switching Probit Model}

Our second approach uses the switching probit model (SPM) developed by Quandt (1958, 1960, 1972) and Heckman (1979) which has been applied in the bivariate probit with 
selection case by van de Ven and van Praag (1981). This model allows us to control for both observables and unobservables, once we make a distributional assumption, when estimating policy effects. Our approach builds on the important work of AHV and the papers they cite. In their paper evaluating the efficacy of a Norwegian vocational training program, AHV introduced an econometric model for estimating different policy parameters, i.e. average treatment effect, marginal treatment effect, and treatment on treated, when the outcome is discrete and the treatment effect is heterogeneous. Our approach differs from that of AHV in several important ways. First, we analyze a program, Medicaid, where a child cannot participate if ineligible, and we exploit this feature in estimation and in calculating treatment effects. Second, Medicaid eligibility--the treatment in our analysis--is observable given family income, state of residence, year and child's age. We use this in calculating policy effects, and it allows us to consider nonmarginal counterfactual Medicaid expansions. In other words, when we conduct a counterfactual policy experiment, we can identify whose treatment status actually changed, and not just the change in the probability of receiving treatment. Knowing who is eligible also allows us to consider how well our models mirror the data. (Note that these features of Medicaid apply to other programs, such as the Supplemental Nutrition Assistance Program.) Third, we show that policy effects based on the SPM can be precisely estimated, at least for the case of Medicaid; this was not the case for AHV. Fourth, we show researchers how pre-programmed commands in Stata can be used to estimate all relevant effects and most standard errors.

One way to proceed is to estimate a joint model with participation in public insurance, participation in private insurance, and public insurance eligibility; however this is quite complicated to estimate since it requires trivariate integration, and there is no preprogrammed routine in Stata to estimate this model. Further, in this model, misspecification in the take-up 
equation will cause bias in the private participation equation and vice-versa. Fortunately, it is straightforward to show that all parameters can be estimated consistently by separately considering two likelihood functions: one containing the parameters for eligibility and for public insurance participation and one containing the parameters for eligibility and for private insurance participation. Using separate likelihood functions has the advantage that misspecification in the public take-up equation will not cause bias in the private participation equation or vice-versa, and the disadvantage that one gives up some efficiency in estimation; these issues are essentially identical to those that come up in the trade-off between two-stage least squares and three-stage least squares.

We first consider the likelihood function containing the parameters for eligibility and for public insurance participation. We assume that the index function for eligibility is

$$
\operatorname{Elig}_{i}^{*}=Z_{i} \delta+e_{i} .
$$

Next, we assume that for a randomly chosen (in terms of unobservables) individual, the index function for participation in public insurance, once being made exogenously eligible for Medicaid, is ${ }^{10}$

$$
\operatorname{PPub}_{i}^{*}=X_{i} \mu+\varepsilon_{i},
$$

where $\left(\varepsilon_{i}, e_{i}\right) \sim$ iid $N\left(0, V_{p u b}\right)$ and $V_{p u b}=\left[\begin{array}{cc}1 & \rho_{\varepsilon, e} \\ \rho_{\varepsilon, e} & 1\end{array}\right]$.

The appropriate log likelihood for eligibility and participation in public insurance is

$$
L=\sum_{\text {elig=1pub }=1} \log \Phi_{2}\left[\left(X_{i} \mu, Z_{i} \delta, \rho_{\varepsilon, e}\right]+\sum_{\text {elig=1,pub }=0} \log \Phi_{2}\left[-X_{i} \mu, Z_{i} \delta,-\rho_{\varepsilon, e}\right]+\sum_{\text {elig }=0} \log \Phi_{1}\left[-Z_{i} \delta\right]\right.
$$

\footnotetext{
${ }^{10}$ Following the econometrics literature, we consider the index function for take-up for a randomly chosen (in terms of $\varepsilon_{i}$ ) child exogenously made eligible; note that this also allows us to do counterfactual policy analysis. However, it is worth emphasizing that unless $\rho_{\varepsilon, e}=0$, those actually eligible will not be a randomly chosen subgroup of the population.
} 
where $\Phi_{2}\left[\square, \square, \rho_{\varepsilon, e}\right]$ is the bivariate standard normal distribution function and $\Phi_{1}(\square)$ is the univariate standard normal distribution function. For Medicaid take-up calculations we will only need the parameters estimated by maximizing (8).

For crowd-out calculations, we also need to incorporate participation in private insurance, so we now consider the likelihood function containing the parameters for eligibility and for private insurance participation. We assume that for a randomly chosen individual, the index function for participation in private insurance, given exogenous eligibility for public insurance, is Priv_elig ${ }_{i}^{*}=X_{i} \gamma_{e}+u_{e i}$

We define the observed outcome variable priv_elig $=1$ if Priv_elig $_{i}{ }^{*}>0$ and zero otherwise. Further, we assume that for a randomly chosen individual the index function for participation in private insurance given exogenous ineligibility for public insurance is

Priv_nelig ${ }_{i}^{*}=X_{i} \gamma_{n e}+u_{n e i}$,

and define priv_nelig ${ }_{i}=1$ if Priv_nelig ${ }_{i}^{*}>0$ and zero otherwise. Finally we assume ${ }^{11}$

$\left(u_{e i}, u_{n e i,}, e_{i}\right) \sim \operatorname{iidN}\left(0, V_{\text {priv }}\right)$ and $V_{\text {priv }}=\left[\begin{array}{lcr}1 & \rho_{12} & \rho_{13} \\ \rho_{12} & 1 & \rho_{23} \\ \rho_{13} & \rho_{23} & 1\end{array}\right]$.

The appropriate log likelihood is

$$
\begin{aligned}
L= & \sum_{\text {elig }=1, \text { priv }=1} \log \Phi_{2}\left[\left(X_{i} \gamma_{e}, Z_{i} \delta, \rho_{n 13}\right]+\sum_{\text {elig }=1, \text { priv }=0} \log \Phi_{2}\left[-X_{i} \gamma_{e}, Z_{i} \delta,-\rho_{n 13}\right]+\right. \\
& \sum_{\text {elig }=0, \text { priv }=1} \log \Phi_{2}\left[\left(X_{i} \gamma_{n e},-Z_{i} \delta,-\rho_{n 23}\right]+\sum_{\text {elig }=0, \text { priv }=0} \log \Phi_{2}\left[-X_{i} \gamma_{n e},-Z_{i} \delta,-\rho_{n 23}\right] .\right.
\end{aligned}
$$

\footnotetext{
${ }^{11}$ Note that $\rho_{12}$ is neither identified nor used in any calculations below.
} 
Unfortunately, even though this likelihood function involves only bivariate integration, there is no preprogrammed routine in Stata to estimate this model. Instead, to obtain an approach that can be implemented with preprogrammed commands in Stata, we randomly divide the sample into two sub-samples. On the first sub-sample we focus on the take-up of private insurance by those eligible for Medicaid and maximize

$$
\begin{aligned}
L_{1}= & \sum_{\text {elig }=1, p \text { priv }=1} \log \Phi_{2}\left[\left(X_{i} \gamma_{e}, Z_{i} \delta, \rho_{n 13}\right]+\sum_{\text {elig }=1, p \text { priv }=0} \log \Phi_{2}\left[-X_{i} \gamma_{e}, Z_{i} \delta,-\rho_{n 13}\right]\right. \\
& +\sum_{\text {elig }=0} \log \Phi_{1}\left[-Z_{i} \delta\right] .
\end{aligned}
$$

Next, on the other sub-sample we focus on the take-up of private insurance by those ineligible for Medicaid and maximize

$$
\begin{aligned}
L_{2}= & \sum_{\text {elig=0, priv }=1} \log \Phi_{2}\left[\left(X_{i} \gamma_{n e},-Z_{i} \delta,-\rho_{n 23}\right]+\sum_{\text {elig=0,priv }=0} \log \Phi_{2}\left[-X_{i} \gamma_{e},-Z_{i} \delta, \rho_{n 23}\right]\right. \\
& +\sum_{\text {elig }=1} \log \Phi_{1}\left[Z_{i} \delta\right] .
\end{aligned}
$$

Note that since we randomly chose the sub-samples, the parameter estimates from (11) and (12) are independent.

The cost of the SPM versus the LPM would seem to be the need for a normality assumption, but interestingly this is not what available Monte Carlo evidence suggests. Angrist (2001) conducts Monte Carlo experiments for a linear probability model with a discrete endogenous regressor estimated by instrumental variables. He finds estimated treatment effects that are very close to those from a properly specified simultaneous equation bivariate probit model. In other words, the simultaneous equation LPM does well with normally distributed errors. However, Bhattacharya et al. (2006) show that the simultaneous equation LPM does not do well when the error terms are not normally distributed. In fact, based on their Monte Carlo 
evidence, Bhattacharya et al. (2006) argue in favor of using simultaneous equation bivariate probit, rather than the linear probability model, when the error terms are not normally distributed. Thus it appears that the LPM estimates are actually more dependent on the normality assumption than are estimates from the simultaneous equation bivariate probit model.

Of course it would be ideal to eliminate the need to make any distributional assumptions, but unfortunately Shaikh and Vytlacil (2005) show that, in general, only bounds on the average effect of treatment can be identified in this case. Further, AHV stress the need for making a distributional assumption for the treatment effects considered below once the relevant parameters have been estimated. Of course, researchers are free to estimate the model with a different distributional assumption, e.g. assume that the error terms are drawn from a mixture of normals (see e.g., Carneiro, Hansen, and Heckman (2003)). We do not adopt this approach since it would force us to violate our commitment to using prewritten Stata modules.

\subsection{Estimating Take-Up and Coverage Effects Using the Switching Probit Model and Ignoring Selection}

In this section we consider take-up and crowd-out while only controlling for observable differences between the marginally eligible and other groups (such as those currently eligible or the newly eligible from a non-marginal expansion), as is the case in our LPMI approach. ${ }^{12}$ The predicted average take-up rate among all currently eligible individuals (the ATET) is obtained from

$$
\operatorname{ATRE}^{\text {spm }}=\sum_{\text {elig=1 }}\left[1-\Phi_{1}\left(-X_{i} \hat{\mu}\right)\right] / N_{e}
$$

\footnotetext{
${ }^{12}$ Below we also use the SPM to examine take-up and crowd-out while controlling for both observable and unobservable differences between the marginally eligible and other eligible groups.
} 
where $\hat{\mu}$ is obtained by maximizing (8). (As in the case of all expressions based on the SPM, the delta method can be used to calculate the standard errors for these predicted take-up rates in Stata. $)^{13}$

One can also calculate take-up for a randomly chosen person over the whole sample (the ATE) as

$$
A T R^{s p m}=\sum_{i=1}^{N}\left[1-\Phi_{1}\left(-X_{i} \hat{\mu}\right)\right] / N
$$

Private insurance coverage rates among the currently eligible are estimated by

$$
\operatorname{PITE}^{s p m}=\sum_{\text {elig=1 }}\left[\operatorname{Pr}\left(X_{i} \gamma_{e}+u_{e i}>0\right] / N_{e}=\sum_{\text {elig }=1}\left[1-\Phi_{1}\left(-X_{i} \hat{\gamma}_{e}\right)\right] / N_{e}\right.
$$

while the analogous expression, if they were ineligible, is given by

$$
\operatorname{PITNE}^{\text {spm }}=\sum_{\text {elig=1 }} \operatorname{Pr}\left(X_{i} \gamma_{n e}+u_{n e i}>0\right) / N_{e}=\sum_{\text {elig=1 }}\left[\left(1-\Phi_{1}\left(-X_{i} \hat{\gamma}_{n e}\right)\right] / N_{e} .\right.
$$

Thus we measure average crowd-out among all those eligible when we ignore selection using

$$
\begin{aligned}
C O^{\text {spm }} & =\sum_{\text {elig=1 }}\left[\operatorname{Pr}\left(X_{i} \gamma_{n e}+u_{n e i}>0\right)-\operatorname{Pr}\left(X_{i} \gamma_{e}+u_{e i}>0\right)\right] / N_{e} \\
& =\sum_{\text {elig=1 }}\left(\left[\left(1-\Phi_{1}\left(-X_{i} \hat{\gamma}_{n e}\right)\right]-\left[\left(1-\Phi_{1}\left(-X_{i} \hat{\gamma}_{e}\right)\right]\right) / N_{e} .\right.\right.
\end{aligned}
$$

Note that we obtain $\hat{\gamma}_{e}$ and $\hat{\gamma}_{n e}$ from maximizing (11) and (12) respectively; since we use separate random samples the estimates are independent and thus we do not need to calculate their covariance in calculating a standard error for (13e). Expressions (13a)-(13e) are analogous to (4a) and (4c)-(4f) respectively for the LPMI.

${ }^{13}$ Details of this calculation are given in our Online Appendix A. If one wants to use analytical derivatives these need to be programmed, but one can avoid this by using numerical derivatives, which are easily calculated. 
We can calculate the effects of non-marginal increases in the income limits in an analogous manner to that used with the LPMI. For example, consider the non-marginal counterfactual policy change of an increase in the Medicaid income limits by $10 \%$ in 1995 as described in section 3.2 above. To calculate the average take-up rate among the newly eligible across all demographic groups using the SPM when we ignore the fact that they will not be a random sample of the population (in terms of $\mathrm{e}_{\mathrm{i}}$ and $\varepsilon_{i}$ ), we use

$T N E W E^{s p m}=\sum_{i \in N e W}\left[1-\Phi_{1}\left(-X_{i} \hat{\mu}\right)\right] / N_{n e w}$

Private insurance coverage rates among the newly eligible in this case are estimated by

$$
\operatorname{PITNEWE}^{\text {spm }}=\sum_{i \in \text { New }}\left[\operatorname{Pr}\left(X_{i} \gamma_{e}+u_{e i}>0\right] / N_{\text {new }}=\sum_{i \in \text { New }}\left[1-\Phi_{1}\left(-X_{i} \hat{\gamma}_{e}\right)\right] / N_{\text {new }}\right.
$$

while the analogous expression, if they were ineligible, is given by

$$
\text { PITNEWNE } E^{\text {spm }}=\sum_{i \in N e w} \operatorname{Pr}\left(X_{i} \gamma_{n e}+u_{n e i}>0\right) / N e w=\sum_{i \in N e w}\left[\left(1-\Phi_{1}\left(-X_{i} \hat{\gamma}_{n e}\right)\right] /\right. \text { New. }
$$

Thus we measure average crowd-out among the new eligible when we ignore selection as

$$
\begin{aligned}
C O^{s p m} & =\sum_{i \in N e w}\left[\operatorname{Pr}\left(X_{i} \gamma_{n e}+u_{n e i}>0\right)-\operatorname{Pr}\left(X_{i} \gamma_{e}+u_{e i}>0\right)\right] / N e w \\
& =\sum_{i \in N e w}\left(\left[\left(1-\Phi_{1}\left(-X_{i} \hat{\gamma}_{n e}\right)\right]-\left[\left(1-\Phi_{1}\left(-X_{i} \hat{\gamma}_{e}\right)\right]\right) / i \in N e w\right.\right.
\end{aligned}
$$

Expressions (14a)-(14d) are analogous to (5a)-(5d) respectively for the LPMI.

3.5 Estimating Take-Up and Coverage Effects Using the Switching Probit Model While Allowing for Selection

In what follows we present the expressions analogous to those in Section 3.4 for the case where we account for the fact that the eligible children will not be a random sample in terms of the error term in the eligibility index (6). In this case, we estimate the average take-up among the eligible (ATET) as 


$$
\begin{aligned}
\operatorname{ATRSELE}^{\text {spm }} & =\frac{1}{N_{e}} \sum_{\text {elig=1 }} \operatorname{Pr}\left(\text { pub }_{i}=1 \mid \text { elig }_{i}=1\right)=\frac{1}{N_{e}} \sum_{\text {elig }=1}\left[\frac{\operatorname{Pr}\left(\text { pub }_{i}=1, \text { elig }_{i}=1\right)}{\operatorname{Pr}\left(\text { elig }_{i}=1\right)}\right] \\
& =\frac{1}{N_{e}} \sum_{\text {elig=1 }} \frac{\Phi_{2}\left(X_{i} \hat{\mu}, Z_{i} \hat{\delta}_{e}, \hat{\rho}_{\varepsilon, e}\right)}{\Phi_{1}\left(Z_{i} \hat{\delta}_{e}\right)}
\end{aligned}
$$

where $\left(\hat{\mu}, \hat{\delta}_{e}, \hat{\rho}_{\varepsilon, e}\right)$ are obtained by maximizing (8). Private insurance coverage rates among the currently eligible are now given by

$$
\begin{aligned}
& \text { PITESEL }^{\text {spm }}=\sum_{\text {elig }=1}\left[\operatorname{Pr}\left(\text { priv_elig }_{i}=1 \mid \text { elig }_{i}=1\right)\right] / N_{e}=\sum_{\text {elig }=1}\left[\frac{\operatorname{Pr}\left(\text { priv_elig }_{i}=1, \text { elig }_{i}=1\right)}{\operatorname{Pr}\left(\text { elig }_{i}=1\right)}\right] / N_{e} \\
& =\left[\sum_{\text {elig }=1} \frac{\Phi_{2}\left(X_{i} \hat{\gamma}_{e}, Z_{i} \hat{\delta}_{1}, \hat{\rho}_{13}\right)}{\Phi_{1}\left(Z_{i} \tilde{\delta}_{1}\right)}\right] / N_{e} .
\end{aligned}
$$

If they were ineligible for Medicaid, these children would have private coverage given by

$$
\begin{aligned}
\text { PRINESEL }^{\text {spm }} & =\sum_{\text {elig }=1}\left[\operatorname{Pr}\left(\text { priv_nelig }_{i}=1 \mid \text { elig }_{i}=1\right)\right] / N_{e}=\sum_{\text {elig=1 }}\left[\frac{\operatorname{Pr}\left(\text { priv_nelig }_{i}=1, \text { elig }_{i}=1\right)}{\operatorname{Pr}\left(\text { elig }_{i}=1\right)}\right] / N_{e} \\
& =\left[\sum_{\text {elig=1 }} \frac{\Phi_{2}\left(X_{i} \hat{\gamma}_{n e}, Z_{i} \hat{\delta}_{2}, \hat{\rho}_{23}\right)}{\Phi_{1}\left(Z_{i} \tilde{\delta}_{2}\right)}\right] / N_{e} .
\end{aligned}
$$

The parameter estimates used in (15b) and (15c) are obtained by maximizing (11) and (12) respectively. Thus crowd-out for the currently eligible is given by ${ }^{14}$

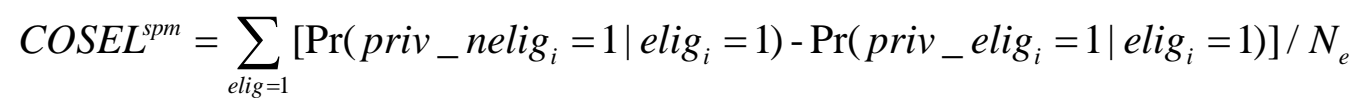

$$
\begin{aligned}
& =\sum_{\text {elig }=1}\left[\frac{\operatorname{Pr}\left(\text { priv_nelig }_{i}=1, \text { elig }_{i}=1\right)}{\operatorname{Pr}\left(\text { elig }_{i}=1\right)}-\frac{\operatorname{Pr}\left(\text { priv_elig }_{i}=1, \text { elig }_{i}=1\right)}{\operatorname{Pr}\left(\text { elig }_{i}=1\right)}\right] / N_{e} \\
& =\left[\sum_{\text {elig }=1} \frac{\Phi_{2}\left(X_{i} \hat{\gamma}_{n e}, Z_{i} \hat{\delta}_{2}, \hat{\rho}_{23}\right)}{\Phi_{1}\left(Z_{i} \widetilde{\delta}_{2}\right)}-\frac{\Phi_{2}\left(X_{i} \hat{\gamma}_{e}, Z_{i} \hat{\delta}_{1}, \hat{\rho}_{13}\right)}{\Phi_{1}\left(Z_{i} \tilde{\delta}_{1}\right)}\right] / N_{e} .
\end{aligned}
$$

\footnotetext{
${ }^{14}$ Moreover, since $\left(\hat{\gamma}_{n e}, \hat{\delta}_{2}, \hat{\rho}_{23}\right)$ are obtained by maximizing (12) on the first random sub-sample and $\left(\hat{\gamma}_{e}, \hat{\delta}_{1}, \hat{\rho}_{13}\right)$ are obtained by maximizing (11) on the second random sub-sample, the estimates are independent and thus the two terms in (15d) are independent.
} 
Note that (15a)-(15d) are analogous to (14a)-(14d) when we use the SPM and ignore selection, as well as (4a) and (4c)-(4f) when we use the LPMI (and also ignore selection).

Next we consider the treatment effects for our counterfactual policy change of raising all income limits by $10 \%$ when we allow for selection. For each individual let $Z_{0 i}$ denote the value of the previous explanatory variables and $Z_{1 i}$ denote the value of the new explanatory variables under the new income limits; note that $Z_{0 i}$ and $Z_{1 i}$ differ only in terms of the value of FRACELIG). Then the probability that a child is newly eligible is given by

$$
\left.\operatorname{Pr}\left(\text { newelig }_{i}\right)=\operatorname{Pr}\left(-Z_{1 i} \delta<e_{i} \leq-Z_{0 i} \delta\right)\right]
$$

In this case average take-up among the newly eligible is given by

$$
\begin{aligned}
\operatorname{TNEWSEL}^{\text {spm }} & =\sum_{i \in \text { New }} \operatorname{Pr}\left(\text { pub }_{i}=1 \mid \text { newelig }_{i}=1\right) / N_{\text {new }}=\sum_{i \in \text { New }}\left[\frac{\operatorname{Pr}\left(\text { pub }_{i}=1, \text { newelig }_{i}=1\right)}{\operatorname{Pr}\left(\text { newelig }_{i}=1\right)}\right] / N_{\text {new }} \\
& =\sum_{i \in N e w} \frac{\Phi_{2}\left(X_{i} \hat{\mu},-Z_{0 i} \hat{\delta}_{e}, \hat{\rho}_{\varepsilon, e}\right)-\Phi_{2}\left(X_{i} \hat{\mu},-Z_{1 i} \hat{\delta}_{e}, \hat{\rho}_{\varepsilon, e}\right)}{\Phi_{1}\left(-Z_{0 i} \hat{\delta}_{e}\right)-\Phi_{1}\left(-Z_{1 i} \hat{\delta}_{e}\right)} / N_{\text {new }}
\end{aligned}
$$

Next note that private insurance coverage for the newly eligible is given by

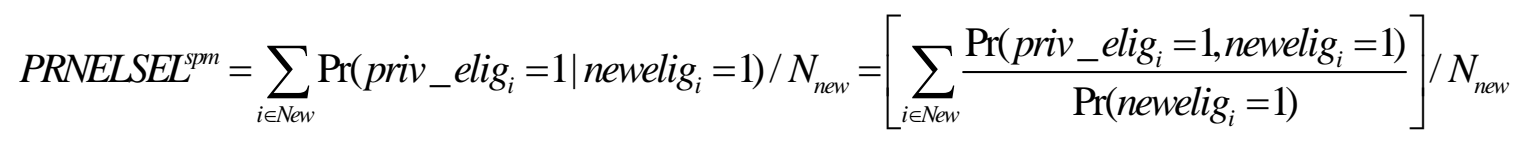

$$
\begin{aligned}
& =\left[\sum_{i \in \text { New }} \frac{\Phi_{2}\left(X_{i} \hat{\gamma}_{e}, Z_{i} \hat{\delta}_{1}, \hat{\rho}_{13}\right)}{\left.Z_{1 i} \delta_{1}\right)-\Phi_{1}\left(-Z_{0 i} \delta_{1}\right)}\right] / N_{\text {new }} .
\end{aligned}
$$

In the absence of becoming eligible, these individuals would have private coverage given by

$$
\begin{aligned}
\text { PRNNESEL }^{\text {spm }} & =\sum_{i \in \text { New }} \operatorname{Pr}\left(\text { priv_nelig }_{i}=1 \mid \text { newelig }_{i}=1\right) / N_{\text {new }} \\
& =\left[\sum_{i \in \text { New }} \frac{\operatorname{Pr}\left(\text { priv_nelig }_{i}=1, \text { newelig }_{i}=1\right)}{\operatorname{Pr}\left(\text { newelig }_{i}=1\right)}\right] / N_{\text {new }} \\
& =\left[\sum_{i \in \text { New }} \frac{\Phi_{2}\left(X_{i} \hat{\gamma}_{\text {ne }}, Z_{i} \hat{\delta}_{2}, \hat{\rho}_{23}\right)}{\Phi_{1 i}\left(-Z_{1}\right)-\Phi_{1}\left(-Z_{0 i} \delta_{2}\right)}\right] / N_{\text {new }} .
\end{aligned}
$$


Thus crowd-out for the newly eligible while accounting for selection is given by ${ }^{15}$

$$
\begin{aligned}
& \text { CNEWSEL }^{\text {spm }}=\left[\sum_{i \in \text { New }} \operatorname{Pr}\left(\text { priv_nelig }_{i}=1 \mid \text { newelig }_{i}=1\right)-\sum_{i \in \text { New }} \operatorname{Pr}\left(\text { priv_elig }_{i}=1 \mid \text { newelig }_{i}=1\right)\right] / N_{\text {new }}
\end{aligned}
$$

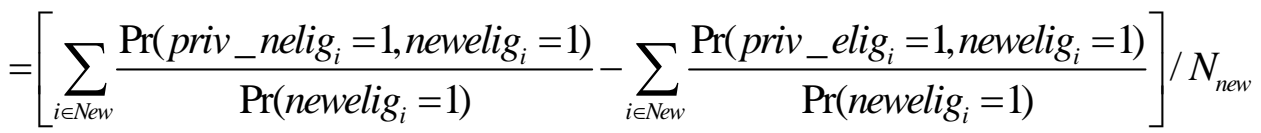

$$
\begin{aligned}
& =\left[\sum_{i \in \text { New }} \frac{\Phi_{2}\left(X_{i} \hat{\gamma}_{n}, Z_{i} \hat{\delta}_{2}, \hat{\rho}_{23}\right)}{\Phi_{1 i}\left(-Z_{1 i}\right)-\Phi_{1}\left(-Z_{0 i} \delta_{2}\right)}-\sum_{i \in \text { New }} \frac{\Phi_{2}\left(X_{i} \hat{\gamma}_{e}, Z_{i} \hat{\delta}_{1}, \hat{\rho}_{13}\right)}{\Phi_{1}\left(-Z_{1 i} \delta_{1}\right)-\Phi_{1}\left(-Z_{0 i} \delta_{1}\right)}\right] / N_{\text {new. }} \text {. }
\end{aligned}
$$

Note that (16a)-(16d) are analogous to (14a)-(14d) where we use the SPM and ignore selection, and (5a)-(5d) where we use the LPMI (and also ignore selection).

\section{Data}

We use data from the SIPP 1986, 1987, 1988, 1990, 1991, 1992, and 1993 panels, which cover the period 1986-1995. The SIPP is a nationally representative longitudinal household survey specifically designed to collect detailed income and program participation information. The recall period between each interview is four months for every individual, and for our panels the panel length ranges from 24 months for the 1988 panel to 40 months for the 1992 panel. The sample universe is the entire U.S., but the Census Bureau did not separately identify state of residence for residents of nine low population states in those panels. Since state of residence information is critical for us to impute Medicaid eligibility, we drop all individuals whose state of residence is not identified. We also restrict our sample to children living in households that are part of the original sample and who are younger than 16 years old at the first time they are observed. Finally, for comparability with earlier studies we drop children who are observed only once, children who leave the sample and then return, and children who move between states

\footnotetext{
${ }^{15}$ Note that the two sums in the last line of (16d) are independent, again simplifying calculating the standard errors.
} 
during the sample period. In total, these omitted observations constitute less than $8 \%$ of the sample.

Although the four-month period increases the probability of accurate reporting, particularly relative to the fifteen-month recall period of the March Current Population Survey (Bennefield 1996), the SIPP suffers from the problem of "seam bias.” Specifically, Census Bureau researchers have shown that there are a disproportionate number of transitions between the last month of the current wave and the first month of the next wave (see, e.g., Young 1989, Marquis and Moore 1990). We use data for all interview months and account for seam bias by including a dummy variable for the fourth month of each interview wave. When we calculate predicted take-up and crowd-out probabilities, we follow Ham, Li, and Shore-Sheppard (2011) and adjust our parameter estimates by dropping the coefficient on the fourth month dummy and adding one-quarter of this coefficient to the intercept. In their study of accounting for seam bias in a multi-state, multi-spell duration model, Ham, Li and Shore-Sheppard (2011) find that this is preferable to using data only from the fourth month of each wave.

We need to impute Medicaid eligibility and use four steps to do so. First, we construct the family unit relevant for Medicaid program participation and determine family income. Second, we assign family-specific poverty thresholds based on the size of the family and the year. Since Medicaid eligibility resulted from AFDC eligibility over this period, we then use information on the family income and family structure, along with the AFDC parameters in effect in the state and year, to impute eligibility for AFDC. Finally, we assign Medicaid eligibility if any of the following conditions hold: the child is in an AFDC-eligible family; the child is income eligible for AFDC and either lives in a state without a family structure requirement or lives in a state with an AFDC-unemployed parent program and has an unemployed parent; or the child's family 
income as a percent of the relevant poverty line is below the Medicaid expansion income eligibility cutoff in effect for that age child in his or her state of residence at that time.

In Table 1 we present the (unweighted) sample means for the variables used in our regressions. Both Medicaid participation and Medicaid eligibility rose over the course of the sample, while private insurance coverage fell. The rise in eligibility was particularly dramatic between the 1988 and 1990 panels, when federally mandated expansions took effect. Compared with the changes in insurance eligibility and coverage, the demographic variables are fairly stable across panels.

\section{Empirical Results}

\subsection{Estimates of LATEs and ATETs on the Currently Eligible for Medicaid Take-Up}

In this section we consider Medicaid treatment effects for the currently eligible. For the purpose of comparison we begin by estimating a LATE using the previous standard in the literature, the LPM. In all of the models we estimate we include demographic variables as well as state, year and age dummies for each child to control for state-specific, age-specific and year-specific unobservables, and since we use longitudinal data, we cluster the standard errors to account for dependence across person-specific observations. ${ }^{16}$ Using the standard LPM, the estimated takeup rate averaged across marginal individuals is a very statistically significant 0.127 . (See column (1) of Table B1 in the Online Appendix.) Since these are IV estimates we need to consider the issue of weak IV in the standard model. We cannot investigate whether our instruments are weak using the rule of thumb for the F-test being greater than 10 suggested by Staiger and Stock

16 Card and Shore-Sheppard (2004) and Shore-Sheppard (2008) suggest including the two-way interactions of state by age, state by year, and age by year in models of Medicaid take-up and private insurance participation to control for differential trends for groups affected by eligibility expansions. This richer model is not feasible to estimate in the SIPP data when interacting all demographic groups with eligibility, but the interactions of eligibility with the year, age, and state dummies serve much the same purpose, allowing for differential trends by eligibility status. 
(1997), or the refinements of their rule in Stock and Yogo (2005), since the F-test is not appropriate if the observations are dependent across the same child or if heteroskedasticity is present. Since the first stage equation is a LPM estimated on panel data, both problems will occur in our application. Instead we use the rule of thumb from Hansen, Hausman, and Newey (2008) that the Wald statistic for the coefficient on the excluded instrument FRACELIG in the first stage equation should be greater than 33 (for one excluded instrument). Since we find that the Wald statistic for the coefficient on FRACELIG is approximately 3,500, we conclude that weak instruments are not an issue here.

Using this basic specification, we next estimate the simultaneous equation LPMI discussed in section 3, allowing the eligibility effect to depend on demographic variables as well as on the state, year and age dummies for each child. ${ }^{17}$ On the issue of weak instruments for the LPMI model, we do not know of a well-developed rule of thumb or test for weak IV in an exactly identified model with $\mathrm{K}$ endogenous variables and error terms that are correlated over time (for the same individual) and heteroskedastic. However, our problem has quite a bit of structure, since we are essentially asking if $F R A C E L I G_{i} * X_{i k}$ is a strong instrument for $e e_{i g} X_{i k}$ over $k=1, \ldots, K$. As our results above indicate that $F R A C E L I G_{i}$ is an excellent instrument for $e \operatorname{lig}_{i}$, we also would expect $F R A C E L I G_{i} * X_{i k}$ to be an excellent instrument for elig $_{i} X_{i k}$, and indeed we find this to be the case in our data. ${ }^{18}$ Finally, if one takes the approach that the

\footnotetext{
${ }^{17}$ The eligibility coefficients for the Medicaid equation are presented in column (3) of Table B1 in the Online Appendix; all coefficients are jointly significant.

${ }^{18}$ When we test the null hypothesis $\lambda_{k}=0$ in the quasi first stage regressions elig $_{i} X_{i k}=\kappa_{1 k} X_{i}+\lambda_{k}\left(\right.$ FRACELIG $\left._{i} * X_{i k}\right)+u_{2 i}, k=1, \ldots, K$, it is reassuring to note that the minimum Chi-Square statistic is 1920, 960, 1280 and 78 for the eligibility*demographics, the eligibility*age dummies, the eligibility* year dummies, and the eligibility*state dummies in the first stage equation, respectively. Of course this is an informal testing procedure, since the tests are not independent. One could avoid this latter problem by testing the null hypothesis $\lambda_{1}=\lambda_{2}=\ldots=\lambda_{K}=0$. Alternatively, if one followed Amemiya
} 
standard errors for the second stage equation are a good indicator of whether one has a weak IV problem when the number of instruments does not grow large with the sample size (see Imbens and Wooldridge 2008), then it is clear that weak instruments are not a problem in our application, unlike that of Blundell, Dearden, and Sianesi (2005).

In column 1 of Table 2 we present LATE estimates from the LPMI for Medicaid take-up, both for the entire population and by demographic group. ${ }^{19}$ These estimates show a great deal of variation across different demographic groups. Ignoring the negative values (for children whose highest earning parent has a college degree or those in families with two or more earners), ${ }^{20}$ the LATE estimates for take-up range from 6 percent for children in the families where both parents are present to 44 percent for children in families without any earners.

Having estimated the LATEs, we next approximate Medicaid take up rates for the eligible (the ATET) by demographic group. ${ }^{21}$ We focus on these parameters as opposed to the average treatment effects (for the general population), since the former are likely to be most useful for policy. ${ }^{22}$ Column (1) of Table 3 contains the ATETs from the LPMI estimates. In column (2) of Table 3 we present the ATETs from the SPM when we ignore the fact that the eligible are not a random sample. Thus, the estimates in columns (1) and (2) are comparable

(1985) and used $\left(X_{i}{ }^{*}\left(Z_{i} \hat{\delta}\right)\right)$ as the vector of instruments for $X_{i}{ }^{*}$ eligi (where $\hat{\delta}$ is estimated by (2)), the test for weak IV would reduce to testing whether $F R A C E L I G_{i}$ is a weak IV for $e l i g_{i}$, and we have already seen that this null hypothesis is decisively rejected by the data.

${ }^{19}$ Column (2) is discussed when we discuss the private coverage results in Section 5.3, below.

${ }^{20}$ Negative probabilities are a common problem in the LPM when estimating probabilities near zero.

${ }^{21}$ We do not present marginal effects for the SPM and compare them to the LATE estimates because it is difficult to know what change in income limits corresponds to the one implicit for a LATE estimate. Of course the marginal estimates from the SPM do have the advantage that they are constrained to be nonnegative.

${ }^{22}$ We do not think that an experiment which makes every American child eligible for Medicaid is particularly interesting from a policy perspective since we believe there is little chance that the US will move to universal government sponsored health care, let alone one based on the current Medicaid system. (We include the relevant expressions for the ATEs since they may be useful in other applications.) 
since neither account for unobservables. ${ }^{23}$ In column (3) of Table 3 we present Medicaid ATETs from the SPM where we take into account the fact that those who are currently eligible for Medicaid are not randomly selected. The estimated ATETs in column (3) for a given demographic group are very similar quantitatively to those from models (1) and (2), except for children from families with two or more earners. All estimates are easily statistically distinguishable from zero. One positive aspect of calculating ATETs with the SPM is that we avoid estimating negative probabilities, which is not true when we use the LPMI. The take-up rates in column (3) are somewhat larger than those in columns (1) and (2) because they take into account the fact (as indicated by our parameter estimates) that those who are eligible for Medicaid have unobservable characteristics that make them more likely to take up Medicaid.

For expositional simplicity we focus on the estimates in column (2) for the SPM, where the ATETs range from 0.08 for children from families with more than two earners to 0.77 for children from families with no earners. The estimates show a clear pattern: eligible children from traditionally disadvantaged groups take up Medicaid at a higher rate than eligible children from typically less disadvantaged groups. Eligible white children have a take-up rate of 0.40 while the take-up rate for non-white children is fifty percent larger. The estimated ATET for children in families in which the family head has less than a high school degree is 0.60 , while it is 0.22 for children in families in which the family head has a college degree or more. Moreover, the takeup rate for an eligible child from a family in which a female is a single head is 0.68 , while it is only 0.27 for a child from a two-parent family. Thus traditionally welfare-ineligible populations

\footnotetext{
${ }^{23}$ The parameter estimates are presented in columns (1) and (2) of Table B2 in the Online Appendix, and the coefficients in the eligibility index function are jointly significant and generally in the expected direction. While to the best of our knowledge there is no rule of thumb for significance of the coefficient on FRACELIG in the eligibility equation, the Wald statistic for this variable is approximately 3600, suggesting that the participation equations for public and private insurance are well identified in the SPM.
} 
have dramatically lower responses to Medicaid eligibility than do the traditionally welfareeligible. While this has been suspected in the literature previously, ours are the first quantitative estimates of the differences in take-up across groups, and they suggest that improving take-up among the eligible requires efforts to promote public coverage primarily among populations that had not previously been eligible for coverage.

Finally, in column (4) of Table 3 we present the sample take-up rates among the different demographic groups; as is the case in columns (1)-(3) we use only the 1995 data. When we compare the predicted take-up rates in the first three columns of Table 3 with the sample take-up rate in column (4), the LPMI (column (1)) and the SPM (column (2)), both of which ignore unobservables, perform equally well in terms of model fit for the demographic groups with higher take-up rates, while the SPM fits the data for the demographic groups with lower take-up rates somewhat better. Second, in terms of fitting the actual take-up rates for the eligible by demographic group, with the exception of the take-up rate for children from families whose highest earner is a college graduate, the SPM that accounts for unobservables (column (3)) performs at least as well, and often notably better than, either the LPMI or the SPM ignoring unobservables. ${ }^{24}$

Tables 2 and 3 demonstrate a significant advantage of the two approaches we explore here over the standard LPM approach. Using the latter, all one can do is use the estimated average take-up rate for all marginal individuals, a group whose composition is unobserved, to predict the effect of an expansion, while our approach permits us to use estimated take-up rates among observable groups of children to predict the effects of an expansion for these different groups. Further, our estimates in column (3) of each table allow us to account for the fact that

\footnotetext{
${ }^{24}$ Given that all calculations necessary for calculating effects along the lines of column (3) are available in our online appendix, these results strongly suggest researchers should use this approach in practice.
} 
currently eligible children or those made eligible by our policy experiment will have different unobservables. We find that many of the predicted take-up rates for different groups are considerably larger than the estimated take-up rate from the standard model.

\subsection{Estimated ATETs on Medicaid Take-up for a Counterfactual Medicaid Eligibility Expansion}

Thus far, we have focused on using our estimates to examine average treatment effects for the currently eligible. However, another advantage offered by our proposed approaches is the ability to do counterfactual policy analysis. In Table 4, we show the predicted take-up rates for children in the 1995 data made newly eligible under a counterfactual policy experiment where we increase the 1995 income limits by 10\%. In column (1) we make this calculation for the LPMI while in column (2) we make this calculation for the SPM while not accounting for unobservable differences. Column (3) shows the estimated take-up rates among newly eligible individuals using the SPM when we allow for selection. The estimates in column (3) are again larger than those in column (2) because of the positive estimated correlation between unobservables in eligibility and unobservables in take-up. As with the actual expansions, there again are differences across groups of the newly eligible in their take-up response to the policy expansion, and again the observably less disadvantaged children have substantially lower estimated rates of enrolling in the Medicaid program for which they are eligible. However, the variation across groups in response to a non-marginal expansion is less than the variation among the currently eligible. For example, the variation in take-up rates by family structure ranges from 0.3 (for children in two-parent families) to 0.72 (for children in female-headed families) when considering actual eligibility, but only 0.2 to 0.46 for a counterfactual expansion. In addition, the overall levels of take-up are lower. This is consistent with a story where conveying information about eligibility to potential participants is more difficult for potential participants who do not 
have social networks for obtaining such information (see Bertrand, Luttmer, and Mullainathan (2000)). However, it is also consistent with newly eligible individuals not enrolling because they have access to private coverage through their parents' employment. We shed some light on this issue by examining the private coverage of the Medicaid eligible in Section 5.3 below.

Comparing the take-up rates predicted for a counterfactual increase in eligibility to the LATE estimates by group (in Table 2, column (1)), the take-up response to the counterfactual expansion is predicted to be generally higher than would be predicted by the LATE estimates. Interestingly, the average take-up rate for marginal individuals of 0.12 estimated from the standard LPM is relatively close to the average take-up rates for newly eligible children from two-earner or two-parent families, suggesting that these latter groups may each approximate the relevant marginal (unknown) individuals in the standard estimates. This interpretation seems especially plausible given that the expansions focused on extending benefits to children in twoparent families.

\subsection{Estimates of LATEs and ATETs for the Currently Medicaid Eligible on Private Insurance Participation and Crowd-out}

To examine the implications of eligibility for private insurance participation and crowd-out, we follow the same approach as above and estimate LATEs using the LPMI and then average treatment effects using the LPMI and the SPM (now for private insurance coverage and crowdout.) ${ }^{25}$ The estimated LATEs for crowd-out are in column (2) of Table 2. There is little

\footnotetext{
${ }^{25}$ When we estimate our LPMI for private insurance, the only statistically significant coefficients are on the eligibility main effect and on the interactions of eligibility with gender, male head and the age of the highest earner (see column (4) of Table B1 in the Online Appendix). Of course, this comes with the caveat that the number of significant coefficients will be affected by the normalization. In the SPM we find that all demographic variables, except for the gender of the child, are statistically significant in both index functions (recall that we estimate separate index functions for a randomly chosen child when the child is, and is not, eligible for Medicaid, respectively_see columns (2) and (4) of Table B2 in the Online Appendix). The signs of the variables are the same in both index functions, indicating that the effect of
} 
evidence of crowd-out among many demographic groups. Among the groups showing any crowd-out (that is, a negative effect statistically distinguishable from zero), the estimates range from 2 percent for children in families with one earner to 12 percent for children in families with a male head.

One reason for the fairly low crowd-out rates shown in Table 2 could be that relatively few of the eligible children have private coverage. We examine the rates of private coverage participation among eligible children using our three models; ${ }^{26}$ the results are in Table 5 . The estimates based on the LPMI are in column (1). Columns (2) and (3) provide our estimates from the SPM when we do not and do account for selection, respectively. These predicted private insurance participation effects are precisely estimated and vary widely across groups. Again the estimates from the LPMI and SPM that do not account for unobservables are very similar. The corresponding estimates from the SPM that account for unobservables are qualitatively similar, though they are smaller, reflecting the negative correlation between the unobservables in the eligibility equation and the private insurance equation. For example, the demographic group with the lowest private insurance coverage for all the model specifications is children from families without any earners; the rate varies between 0.12 (from the SPM accounting for unobservables) and 0.16 (from the SPM with unobservables ignored). The highest variation in the estimated coverage rates among different models is for the children in families with two earners; it is 0.86 for the LPMI model and 0.61 for the SPM with unobservables accounted for. Column (4) reports actual private insurance coverage rates in the data and shows that the predicted rates from the SPM accounting for unobservables mirror the data remarkably well.

demographic variables on the index functions for private insurance coverage is in the same direction when a child is eligible for Medicaid as when the child is not eligible.

${ }^{26}$ Again all columns in this Table are based on 1995 data. 
Estimated crowd-out rates among the eligible across demographic groups are reported in Table 6. The crowd-out estimates for the LPMI in column (1) are small, and while only about half are statistically significant, the standard errors indicate that the crowd-out effects have narrow confidence intervals. The results for the SPM when we do not control for selection in column (2) are qualitatively similar to those from the LPMI, although they are smaller in most cases and have even narrower confidence intervals. When we account for selection in column (3), the confidence intervals widen, resulting in only one estimate that is statistically distinguishable from zero. Nevertheless, the pattern of coefficients is quite similar to those in the other two columns. Although there is some evidence that crowd-out rates are higher for groups that have higher levels of private insurance coverage (children in families where the highest earner has some college or is a high school graduate exhibit higher levels of crowding out and higher rates of private coverage than children in families where the highest earner does not have a high school degree, for example), this explanation is clearly not the only one, as crowd-out rates are generally highest (though still small) among groups with the largest take-up responses.

\subsection{Estimates of ATETs on Private Insurance Participation and Crowd-out for a Counterfactual Medicaid Eligibility Expansion}

In Table 7 we use our estimates to predict private insurance coverage rates among those made newly eligible by a 10\% increase in the 1995 Medicaid income limits. ${ }^{27}$ Again columns (1), (2), and (3) present the estimates based on the LPMI, the SPM without accounting for selection and the SPM accounting for selection, respectively. All of these coverage rates are precisely estimated, and as expected, are higher than the respective coverage rates for all eligible children in Table 6 (although similar qualitatively). Again the estimates based on the LPMI and SPM

\footnotetext{
${ }^{27}$ The SPM estimates of the private insurance participation index functions for those who are and are not eligible for Medicaid are in columns (3) and (4) respectively of Table B2 in the Online Appendix.
} 
without allowing for selection are larger than those in column (3) for the SPM while allowing for selection. To consider one group, families without an earner, the private insurance coverage rate goes up to $0.24,0.23$ and 0.16 for the LPMI, the SPM not accounting for unobservables and the SPM while accounting for observables.

We calculate crowd-out across different demographic groups for those made newly eligible by a $10 \%$ increase in the 1995 Medicaid income limits in Table 8 . For the LPMI in column (1), the crowd-out rates are generally statistically insignificant and many of the point estimates are actually positive (indicating increases in private coverage with eligibility). However, the confidence intervals are quite large for these effects. When we use the SPM but do not account for unobservables, all but two of the estimates indicate that Medicaid eligibility reduces private insurance coverage, as expected. However, the estimated magnitudes are quite small and despite quite narrow confidence intervals, we cannot reject the null hypothesis of no effect on private coverage for most groups of newly eligible children. The exceptions are children in families where the highest earner is a high school graduate or has some college, children in families where the head is female, or children in families where there is just one earner. Finally, when we use the SPM estimates and account for selection in Column (3), all of the point estimates indicate that Medicaid eligibility reduces private coverage, but the confidence intervals are so wide that we are unable to say anything definitive about the impact of the counterfactual expansion on private coverage crowd-out using this model.

\section{Conclusions}

In this paper we demonstrate how two approaches—a linear probability model with interactions (LPMI) and a switching probit model (SPM)—can be used to estimate a variety of marginal and non-marginal effects of Medicaid eligibility on Medicaid take-up, private insurance 
coverage, and crowd-out across different demographic groups. These are the first such estimates available in the literature on the effects of Medicaid expansions. We first estimate LATEs for Medicaid eligibility, and find that the LATEs for take-up and crowd-out vary widely across demographic groups. Next, we predict take-up, private insurance coverage and crowd-out for those eligible under the current system. These estimates are precise and again vary substantially across the different demographic groups. We find that take-up is predicted to be highest among typically disadvantaged groups, but that crowd-out is predicted to be most substantial among slightly different groups, including children in families with earners that have somewhat more education. Perhaps surprisingly, crowd-out does not appear to be higher among eligible children in groups with higher levels of private coverage originally. The pattern of take-up and crowd-out effects suggests an important role for information provision and information flows in determining insurance coverage following an expansion.

Finally, we use our approaches to estimate the effects of a counterfactual non-marginal expansion of eligibility. All estimation methods produce sensible and relatively precise effects for Medicaid take-up and private insurance coverage among the newly eligible. We find Medicaid take-up rates following a counterfactual expansion are predicted to be substantially lower than take-up rates among the currently eligible, while private coverage rates are predicted to be substantially higher for the newly eligible. However, estimating crowd-out effects among the newly eligible is more challenging, and we find only the SPM when we do not allow for selection produces confidence intervals for crowd-out among the newly eligible which will be useful for policy makers. Overall, our results provide important information for policymakers about differences in response to eligibility across observable demographic groups, as well as information about how responses to eligibility differ between individuals who were previously 
eligible and those made newly eligible by a counterfactual Medicaid expansion. In addition, the approaches we used here are useful not only in the context of the Medicaid program, but can also be used in evaluating the effects of many other social programs that rely on observable eligibility criteria, such as food and nutrition programs. 


\section{References}

Aakvik, A., Heckman, J. J., and Vytlacil, E. J. (2005), “Estimating Treatment Effects for

Discrete Outcomes When Responses to Treatment Vary: An Application to Norwegian Vocational Rehabilitation Programs,” Journal of Econometrics 125, $15-51$.

Amemiya, T., (1985), Advanced Econometrics, Harvard University Press, Cambridge, MA.

Angrist, J. D., (2001), "Estimation of Limited Dependent Variable Models with Dummy Endogenous Regressor: Simple Strategies for Empirical Practice,” Journal of Business and Economic Statistics 19, 2-16.

Angrist, J. D., (2004), “Treatment Effect Heterogeneity in Theory and Practice,” Economic Journal 114, 52-83.

Bennefield, R.L., (1996), “A Comparative Analysis of Health Insurance Coverage Estimates:

Data from CPS and SIPP,” U.S. Bureau of the Census SIPP Working Paper No. 218.

Bertrand, M., Luttmer, E. F. P., and Mullainathan, S., (2000), "Network Effects and Welfare Cultures,” Quarterly Journal of Economics 115, 1019-1055.

Bhattacharya, J., Goldman, D., and McCaffrey, D., (2006), “Estimating Probit Models with SelfSelected Treatments,” Statistics in Medicine 25, 389-413.

Blumberg, L. J., Dubay, L., and Norton, S. A., (2000), "Did the Medicaid Expansions for Children Displace Private Insurance? An Analysis Using the SIPP,” Journal of Health Economics 19, 33-60.

Blundell, R., Dearden, L., and Sianesi, B., (2005), "Evaluating the Effect of Education on Earnings: Models, Methods and Results from the National Child Development Survey,” Journal of the Royal Statistical Society. Series A (Statistics in Society) 168, 473-512. 
Card, D. and Payne, A. A., (2002), "School Finance Reform, the Distribution of School Spending, and the Distribution of Student Test Scores,” Journal of Public Economics 83, 49-82.

Carneiro, P., Heckman J.J. and Vytlacil, E.J, (2010), "Estimating Marginal Returns to Education,” American Economic Review forthcoming.

Carneiro, P., Hansen, K., and Heckman J.J. (2003), “Estimating Distributions of Treatment Effects with an Application to the Returns to Schooling and Measurement,” International Economic Review 44, 361-422

Currie, J. and Gruber, J., (1996a), “Saving Babies: The Efficacy and Cost of Recent Expansions of Medicaid Eligibility for Pregnant Women,” Journal of Political Economy 104, 1263-1296. , (1996b), “Health Insurance Eligibility, Utilization of Medical Care, and Child Health,” Quarterly Journal of Economics 111, 431-466.

Cutler, D. M. and Gruber, J., (1996), “Does Public Insurance Crowd Out Private Insurance?” Quarterly Journal of Economics 111, 391-430.

Dubay, L. C. and Kenney, G. M., (1996), “The Effects of Medicaid Expansions on Insurance Coverage of Children,” The Future of Children 6, 152-161.

Gruber, J. and Simon, K., (2008), “Crowd-out 10 Years Later: Health Insurance?” Journal of Health Economics 27, 201-217.

Ham, J. C., Li, X., and Shore-Sheppard, L. D., (2011), “Seam Bias, Multiple-State, MultipleSpell Duration Models and the Employment Dynamics of Disadvantaged Women,” Mimeo, University of Maryland.

Ham, J. C. and Shore-Sheppard, L. D., (2005), “The Effect of Medicaid Expansions for LowIncome Children on Medicaid Participation and Private Insurance Coverage: Evidence from the SIPP,” Journal of Public Economics 89, 57-83. 
Hansen, C., Hausman, J. and Newey, W., (2008), "Many Weak Instruments and Microeconomic Practice,” Journal of Business and Economic Statistics 26, 398-422.

Heckman, J. J., (1979), “Sample Selection Bias as a Specification Error,” Econometrica 47, 153161.

Heckman, J. J., Smith, J., and Clements, N., (1997), “Making the Most Out of Programme Evaluations and Social Experiments: Accounting for Heterogeneity in Programme Impacts,” The Review of Economic Studies, 64, 487-535

Hudson, J. L., Selden, T. M., and Banthin, J. S., (2005), "The Impact of SCHIP on Insurance Coverage of Children,” Inquiry 42, 232-54.

Imbens, G. and Wooldridge, J. (2008), Lecture 15 in the IRP (Madison) Workshop on Applied Microeconomics, available at: http://www.irp.wisc.edu/newsevents/workshops/appliedmicroeconometrics/schedule1.htm .

LoSasso, A. T. and Buchmueller, T. C, (2004), "The Effect of the State Children's Health Insurance Program on Health Insurance Coverage,” Journal of Health Economics 23, 10591082.

Marquis, K. H. and Moore, J. C., (1990), "Measurement Errors in the Survey of Income and Program Participation Program Reports,” 1990 Annual Research Conference Proceedings, Washington, D.C.: U. S. Bureau of the Census.

Moffitt, R., (2007), “Estimating Marginal Returns to Higher Education in the UK,” NBER Working Paper 13534.

Quandt, R. E., (1958), “The Estimation of the Parameters of a Linear Regression System Obeying Two Separate Regimes,” Journal of the American Statistical Association 53, 873-880. 
, (1960), “Tests of the Hypothesis That a Linear Regressions System Obeys Two Different Regimes,” Journal of the American Statistical Association 55, 324-330.

_ (1972), “A New Approach to Estimating Switching Regression,” Journal of the American Statistical Association 67, 306-310.

Selden, T. M., Banthin, J. S., and Cohen, J. W., (1998), “Medicaid’s Problem Children: Eligible but not Enrolled,” Health Affairs 17, 192-200.

Shaikh, A. M. and Vytlacil, E. J., (2005), "Threshold Crossing Models and Bounds on Treatment Effects: A Nonparametric Analysis,” NBER Technical Working Paper No. 307.

Shore-Sheppard, L. D., (2000), "The Effect of Expanding Medicaid Eligibility on the Distribution of Children's Health Insurance Coverage," Industrial and Labor Relations Review 54, 59-71. , (2008), "Stemming the Tide? The Effect of Expanding Medicaid Eligibility on Health Insurance Coverage,” The B.E. Journal of Economic Analysis and Policy: 8 (Advances), Article 6, available at: http://www.bepress.com/bejeap/vol8/iss2/art6.

Staiger, D. and Stock, J., (1997), “Instrumental Variables Regression with Weak Instruments,” Econometrica 65, 557-286.

Stock, J. H. and Yogo, M., (2005), “Testing for Weak Instruments in Linear IV Regression,” in J.H. Stock and D.W.K. Andrews, eds., Identification and Inference for Econometric Models: A Festschrift in Honor of Thomas Rothenberg, Cambridge University Press, Cambridge, MA, pp. 80-108.

Thorpe, K. E. and Florence, C. S., (1998), "Health Insurance among Children: The Role of Expanded Medicaid Coverage,” Inquiry 35, 369-379. 
Van de Ven, W. P. M. M. and Van Praag, B. M. S., (1981), "The Demand for Deductibles in Private Health Insurance,” Journal of Econometrics 17, 229-252.

Yazici, E., Kaestner, R., (2000), “Medicaid Expansions and the Crowding Out of Private Health Insurance Among Children,” Inquiry 37, 23- 32.

Young, N., (1989), "Wave-seam Effects in the SIPP,” Proceedings of the Section on Survey Research Methods, Alexandria, VA: American Statistical Association Annual Meeting, 393-398. 
Table 1: Means of the Variables Used in Estimation

\begin{tabular}{lrrrrrrc}
\hline SIPP Panel & 1986 & 1987 & 1988 & 1990 & 1991 & 1992 & 1993 \\
\hline Medicaid & 0.12 & 0.12 & 0.11 & 0.16 & 0.17 & 0.18 & 0.20 \\
Private Coverage & 0.73 & 0.75 & 0.75 & 0.71 & 0.73 & 0.71 & 0.69 \\
Imputed Eligibility & 0.19 & 0.18 & 0.18 & 0.27 & 0.29 & 0.31 & 0.34 \\
Size of Health Insurance Unit & 4.22 & 4.16 & 4.18 & 4.16 & 4.22 & 4.17 & 4.22 \\
White & 0.83 & 0.83 & 0.82 & 0.78 & 0.82 & 0.80 & 0.81 \\
Male & 0.51 & 0.51 & 0.51 & 0.51 & 0.51 & 0.52 & 0.51 \\
Two Parents & 0.76 & 0.77 & 0.77 & 0.71 & 0.74 & 0.73 & 0.73 \\
Male Head Only & 0.02 & 0.02 & 0.02 & 0.03 & 0.03 & 0.03 & 0.02 \\
No Earners & 0.14 & 0.13 & 0.13 & 0.16 & 0.15 & 0.16 & 0.16 \\
One Earner & 0.41 & 0.42 & 0.42 & 0.43 & 0.42 & 0.41 & 0.41 \\
Two Earners & 0.38 & 0.39 & 0.40 & 0.37 & 0.38 & 0.38 & 0.38 \\
Age of Highest Earner & 36.49 & 36.47 & 36.49 & 36.67 & 36.90 & 36.89 & 37.10 \\
Education of Highest Earner & 12.68 & 12.69 & 12.84 & 12.74 & 12.92 & 12.95 & 12.95 \\
FRACELIG & 0.20 & 0.19 & 0.19 & 0.28 & 0.30 & 0.32 & 0.34 \\
\hline $\begin{array}{l}\text { Years Covered } \\
\text { Number of Observations }\end{array}$ & 175709 & 182307 & 163165 & 397187 & 267589 & 433545 & 406833 \\
\hline $\begin{array}{l}\text { Notes: Shown are unweighted means from the respective SIPP panels noted above. See the text for a } \\
\text { description of the sample construction. }\end{array}$ & & & & & & \\
\hline
\end{tabular}


Table 2: LATE Estimates for Medicaid Take-Up and Private Insurance Crowd-Out Among Different Demographic Groups

\begin{tabular}{lcc}
\hline Group & $\begin{array}{c}\text { Medicaid Take-Up } \\
(1)\end{array}$ & $\begin{array}{c}\text { Private Insurance Crow } \\
(2)\end{array}$ \\
& & \\
All Population & $0.12^{* * *}$ & 0.00 \\
& $(0.01)$ & $(0.01)$ \\
Race & $0.11^{* * *}$ & 0.01 \\
White & $(0.01)$ & $(0.01)$ \\
& $0.20^{* * *}$ & -0.00 \\
Non-White & $(0.01)$ & $(0.02)$ \\
& & \\
Education of Highest Earner & $0.24^{* * *}$ & $-0.03^{* * *}$ \\
High School Drop-out & $(0.01)$ & $(0.01)$ \\
& $0.13^{* * *}$ & 0.00 \\
High School Graduate & $(0.01)$ & $(0.01)$ \\
& $0.08^{* * *}$ & 0.02 \\
Some College & $(0.01)$ & $(0.02)$ \\
College Graduate & -0.02 & $0.06^{* * *}$ \\
& $(0.02)$ & $(0.02)$
\end{tabular}

Family Structure

Female Head

$0.30 * * *$

$(0.01)$

$-0.06 * * *$

Male Head

$0.09 * * *$

$(0.02)$

$(0.03)$

$-0.12 * *$

Two parents

$0.06^{* * *}$

(0.03)

(0.01)

$0.04 * * *$

Number of Earners

No earner

$\begin{array}{ll}\text { No earner } & 0.44^{* * *} \\ & (0.02) \\ \text { One earner } & 0.16^{* * *} \\ & (0.01) \\ \text { Two earners } & -0.04 \\ & (0.02) \\ \text { More than two earners } & -0.12 \\ & (0.03)\end{array}$

(0.02)

$-0.11 * * *$

$(0.02)$

$-0.02 * * *$

(0.01)

$0.11^{* * *}$

$(0.02)$

0.03

(0.05)

Notes: All regressions/index functions include demographic main effects, year, age, state dummies, and a fourth month dummy. Standard errors have been corrected for repeated observations across the same children. ${ }^{* * *}$ significantly different from zero at the $1 \%$ level; ${ }^{* *}$ significantly different from zero at the $5 \%$ level; * significantly different from zero at $10 \%$ level. 
Table 3: Estimated Medicaid Average Take-up Rates for All Eligible Children From the Linear Probability Model with Interactions and the Switching Probit Model

\begin{tabular}{|c|c|c|c|c|}
\hline Group & $\begin{array}{l}\text { LPMI } \\
(1)\end{array}$ & $\begin{array}{l}\text { SPM - Unobservables } \\
\text { Ignored } \\
(2)\end{array}$ & $\begin{array}{c}\text { SPM - Unobservables } \\
\text { Accounted for } \\
\text { (3) }\end{array}$ & $\begin{array}{l}\text { Actual } \\
\text { (4) }\end{array}$ \\
\hline All Population & $\begin{array}{l}0.47 * * * \\
(0.03)\end{array}$ & $\begin{array}{l}0.47^{* * * *} \\
(0.01)\end{array}$ & $\begin{array}{l}0.51 * * * \\
(0.02)\end{array}$ & 0.51 \\
\hline \multicolumn{5}{|l|}{ Race } \\
\hline White & $\begin{array}{l}0.41^{* * *} \\
(0.03)\end{array}$ & $\begin{array}{l}0.40 * * * \\
(0.01)\end{array}$ & $\begin{array}{l}0.44 * * * \\
(0.02)\end{array}$ & 0.44 \\
\hline Non-White & $\begin{array}{l}0.62^{* * *} \\
(0.03)\end{array}$ & $\begin{array}{l}0.64^{* * * *} \\
(0.01)\end{array}$ & $\begin{array}{l}0.68 * * * \\
(0.02)\end{array}$ & 0.67 \\
\hline \multicolumn{5}{|c|}{ Education of Highest Earner } \\
\hline High School Drop-out & $\begin{array}{l}0.61^{* * * *} \\
(0.04)\end{array}$ & $\begin{array}{l}0.60 * * * \\
(0.01)\end{array}$ & $\begin{array}{l}0.62 * * * \\
(0.02)\end{array}$ & 0.63 \\
\hline High School Graduate & $\begin{array}{l}0.44^{* * *} \\
(0.03)\end{array}$ & $\begin{array}{l}0.44^{* * *} \\
(0.01)\end{array}$ & $\begin{array}{l}0.48 * * * \\
(0.02)\end{array}$ & 0.49 \\
\hline Some College & $\begin{array}{l}0.38 * * * \\
(0.03)\end{array}$ & $\begin{array}{l}0.40^{* * *} \\
(0.01)\end{array}$ & $\begin{array}{l}0.44^{* * *} \\
(0.02)\end{array}$ & 0.44 \\
\hline College Graduate & $\begin{array}{l}0.19 * * * \\
(0.03)\end{array}$ & $\begin{array}{l}0.22 * * * \\
(0.01)\end{array}$ & $\begin{array}{l}0.27 * * * \\
(0.01)\end{array}$ & 0.16 \\
\hline \multicolumn{5}{|l|}{ Family Structure } \\
\hline Female Head & $\begin{array}{l}0.68 * * * \\
(0.04)\end{array}$ & $\begin{array}{l}0.69 * * * \\
(0.01)\end{array}$ & $\begin{array}{l}0.72 * * * \\
(0.02)\end{array}$ & 0.71 \\
\hline Male Head & $\begin{array}{l}0.31^{* * *} \\
(0.04)\end{array}$ & $\begin{array}{l}0.28 * * * \\
(0.02)\end{array}$ & $\begin{array}{l}0.32 * * * \\
(0.03)\end{array}$ & 0.30 \\
\hline Two parents & $\begin{array}{l}0.27^{* * *} \\
(0.03)\end{array}$ & $\begin{array}{l}0.26^{* * * *} \\
(0.01)\end{array}$ & $\begin{array}{l}0.30^{* * * *} \\
(0.02)\end{array}$ & 0.31 \\
\hline \multicolumn{5}{|l|}{ Number of Earners } \\
\hline No earner & $\begin{array}{l}0.78 * * * \\
(0.04)\end{array}$ & $\begin{array}{l}0.77 * * * \\
(0.005)\end{array}$ & $\begin{array}{l}0.79 * * * \\
(0.02)\end{array}$ & 0.78 \\
\hline One earner & $\begin{array}{l}0.28 * * * \\
(0.03)\end{array}$ & $\begin{array}{l}0.28 * * * \\
(0.01)\end{array}$ & $\begin{array}{l}0.32 * * * \\
(0.03)\end{array}$ & 0.33 \\
\hline Two earners & $\begin{array}{l}0.09 * * \\
(0.04)\end{array}$ & $\begin{array}{l}0.12^{* * *} \\
(0.01)\end{array}$ & $\begin{array}{l}0.18^{* * *} \\
(0.02)\end{array}$ & 0.17 \\
\hline More than two earners & $\begin{array}{l}-0.03 \\
(0.05)\end{array}$ & $\begin{array}{l}0.08^{* * * *} \\
(0.01)\end{array}$ & $\begin{array}{l}0.12^{* * * *} \\
(0.02)\end{array}$ & 0.14 \\
\hline
\end{tabular}

Notes: See notes to Table 2. All regressions/index functions include demographic main effects, year, age, state dummies, eligibility-year, eligibility-age and eligibility-state interactions and a fourth month dummy. Estimates are based on coefficients estimated using data from all SIPP panels and Medicaid eligible children in the 1995 data. 
Table 4: Counterfactual Policy Analysis: Estimated Medicaid Take-up Rates for the Newly Eligible after Raising the 1995 Income Limits by 10\%

\begin{tabular}{|c|c|c|c|}
\hline Group & $\begin{array}{l}\text { LPMI } \\
\text { (1) }\end{array}$ & $\begin{array}{c}\text { SPM - Unobservables } \\
\text { Ignored } \\
(2)\end{array}$ & $\begin{array}{l}\text { SPM- Unobservables } \\
\text { Accounted for } \\
\text { (3) }\end{array}$ \\
\hline All Newly Eligible Population & $\begin{array}{l}0.21 * * * \\
(0.05)\end{array}$ & $\begin{array}{l}0.21 * * * \\
(0.01)\end{array}$ & $\begin{array}{l}0.27 * * * \\
(0.01)\end{array}$ \\
\hline \multicolumn{4}{|l|}{ Race } \\
\hline White & $\begin{array}{l}0.18 * * * \\
(0.05)\end{array}$ & $\begin{array}{l}0.18 * * * \\
(0.01)\end{array}$ & $\begin{array}{l}0.24 * * * \\
(0.01)\end{array}$ \\
\hline Non-White & $\begin{array}{l}0.31^{* * * *} \\
(0.05)\end{array}$ & $\begin{array}{l}0.32^{* * * *} \\
(0.01)\end{array}$ & $\begin{array}{l}0.38^{* * * *} \\
(0.01)\end{array}$ \\
\hline \multicolumn{4}{|l|}{ Education of Highest Earner } \\
\hline High School Drop-out & $\begin{array}{l}0.30 * * * \\
(0.05)\end{array}$ & $\begin{array}{l}0.28 * * * \\
(0.01)\end{array}$ & $\begin{array}{l}0.33 * * * \\
(0.01)\end{array}$ \\
\hline High School Graduate & $\begin{array}{l}0.21^{* * *} \\
(0.05)\end{array}$ & $\begin{array}{l}0.21^{* * *} \\
(0.01)\end{array}$ & $\begin{array}{l}0.26^{* * *} \\
(0.01)\end{array}$ \\
\hline Some College & $\begin{array}{l}0.20 * * * \\
(0.05)\end{array}$ & $\begin{array}{l}0.21 \text { *** } \\
(0.01)\end{array}$ & $\begin{array}{l}0.27 * * * \\
(0.01)\end{array}$ \\
\hline College Graduate & $\begin{array}{c}0.07 \\
(0.06)\end{array}$ & $\begin{array}{l}0.11^{* * *} \\
(0.01)\end{array}$ & $\begin{array}{l}0.17 * * * \\
(0.01)\end{array}$ \\
\hline \multicolumn{4}{|l|}{ Family Structure } \\
\hline Female Head & $\begin{array}{l}0.38 * * * \\
(0.05)\end{array}$ & $\begin{array}{l}0.39 * * * \\
(0.01)\end{array}$ & $\begin{array}{l}0.46 * * * \\
(0.01)\end{array}$ \\
\hline Male Head & $\begin{array}{l}0.15^{* * *} \\
(0.06)\end{array}$ & $\begin{array}{l}0.16^{* * * *} \\
(0.02)\end{array}$ & $\begin{array}{l}0.21 * * * \\
(0.02)\end{array}$ \\
\hline Two parents & $\begin{array}{l}0.15^{* * * *} \\
(0.05)\end{array}$ & $\begin{array}{l}0.15^{* * * *} \\
(0.01)\end{array}$ & $\begin{array}{l}0.20 * * * \\
(0.01)\end{array}$ \\
\hline Number of Earners & & & \\
\hline No earner & $\begin{array}{l}0.63 * * * \\
(0.05)\end{array}$ & $\begin{array}{l}0.63 * * * \\
(0.01)\end{array}$ & $\begin{array}{l}0.66 * * * \\
(0.01)\end{array}$ \\
\hline One earner & $\begin{array}{l}0.23^{* * *} \\
(0.05)\end{array}$ & $\begin{array}{l}0.22^{* * * *} \\
(0.01)\end{array}$ & $\begin{array}{l}0.28 * * * \\
(0.01)\end{array}$ \\
\hline Two earners & $\begin{array}{c}0.09 \\
(0.06)\end{array}$ & $\begin{array}{l}0.11 \text { *** } \\
(0.01)\end{array}$ & $\begin{array}{l}0.17 * * * \\
(0.01)\end{array}$ \\
\hline More than two earners & $\begin{array}{l}-0.07 \\
(0.07)\end{array}$ & $\begin{array}{l}0.06^{* * * *} \\
(0.01)\end{array}$ & $\begin{array}{l}0.11^{* * * *} \\
(0.02)\end{array}$ \\
\hline
\end{tabular}

Notes: See notes to Table 3. Estimates are based on coefficients estimated using data from all SIPP panels and children in the 1995 data made newly eligible by the increase in the Medicaid income limits. 
Table 5: Estimated Average Private Insurance Coverage Rates for All Eligible Children From the Linear Probability Model with Interactions and the Switching Probit Model

\begin{tabular}{|c|c|c|c|c|}
\hline Group & $\begin{array}{l}\text { LPMI } \\
(1)\end{array}$ & $\begin{array}{c}\text { SPM - Unobservables } \\
\text { Ignored } \\
(2)\end{array}$ & $\begin{array}{l}\text { SPM - Unobservables } \\
\text { Accounted for } \\
\text { (3) }\end{array}$ & $\begin{array}{l}\text { Actual } \\
\text { (4) }\end{array}$ \\
\hline All Population & $\begin{array}{l}0.44^{* * *} \\
(0.01)\end{array}$ & $\begin{array}{l}0.44^{* * *} \\
(0.01)\end{array}$ & $\begin{array}{l}0.34^{* * *} \\
(0.03)\end{array}$ & 0.34 \\
\hline \multicolumn{5}{|l|}{ Race } \\
\hline White & $\begin{array}{l}0.50 * * * \\
(0.01)\end{array}$ & $\begin{array}{l}0.50 * * * \\
(0.01)\end{array}$ & $\begin{array}{l}0.39 * * * \\
(0.03)\end{array}$ & 0.38 \\
\hline Non-White & $\begin{array}{l}0.31^{* * *} \\
(0.01)\end{array}$ & $\begin{array}{l}0.30^{* *} \\
(0.01)\end{array}$ & $\begin{array}{l}0.23 * * * \\
(0.02)\end{array}$ & 0.22 \\
\hline \multicolumn{5}{|c|}{ Education of Highest Earner } \\
\hline High School Drop-out & $\begin{array}{l}0.25 * * * \\
(0.01)\end{array}$ & $\begin{array}{l}0.26^{* * * *} \\
(0.01)\end{array}$ & $\begin{array}{l}0.19 * * * \\
(0.02)\end{array}$ & 0.18 \\
\hline High School Graduate & $\begin{array}{l}0.49 * * * \\
(0.01)\end{array}$ & $\begin{array}{l}0.49 * * * \\
(0.01)\end{array}$ & $\begin{array}{l}0.37^{* * *} \\
(0.03)\end{array}$ & 0.36 \\
\hline Some College & $\begin{array}{l}0.58^{* * *} \\
(0.01)\end{array}$ & $\begin{array}{l}0.57^{* * *} \\
(0.01)\end{array}$ & $\begin{array}{l}0.44^{* * *} \\
(0.03)\end{array}$ & 0.46 \\
\hline College Graduate & $\begin{array}{l}0.81 * * * \\
(0.02)\end{array}$ & $\begin{array}{l}0.79 * * * \\
(0.01)\end{array}$ & $\begin{array}{l}0.64^{* * * *} \\
(0.04)\end{array}$ & 0.69 \\
\hline \multicolumn{5}{|l|}{ Family Structure } \\
\hline Female Head & $\begin{array}{l}0.27 * * * \\
(0.01)\end{array}$ & $\begin{array}{l}0.27 * * * \\
(0.01)\end{array}$ & $\begin{array}{l}0.21 * * * \\
(0.02)\end{array}$ & 0.21 \\
\hline Male Head & $\begin{array}{l}0.42^{* * *} \\
(0.03)\end{array}$ & $\begin{array}{l}0.49 * * * \\
(0.02)\end{array}$ & $\begin{array}{l}0.36^{* * *} \\
(0.04)\end{array}$ & 0.37 \\
\hline Two parents & $\begin{array}{l}0.62^{* * *} \\
(0.01)\end{array}$ & $\begin{array}{l}0.61 * * * \\
(0.01)\end{array}$ & $\begin{array}{l}0.47^{* * *} \\
(0.04)\end{array}$ & 0.46 \\
\hline \multicolumn{5}{|l|}{ Number of Earners } \\
\hline No earner & $\begin{array}{l}0.14^{* * *} \\
(0.01)\end{array}$ & $\begin{array}{l}0.16 * * * \\
(0.04)\end{array}$ & $\begin{array}{l}0.12 * * * \\
(0.01)\end{array}$ & 0.13 \\
\hline One earner & $\begin{array}{l}0.62 * * * \\
(0.01)\end{array}$ & $\begin{array}{l}0.62 * * * \\
(0.01)\end{array}$ & $\begin{array}{l}0.47^{* * *} \\
(0.04)\end{array}$ & 0.46 \\
\hline Two earners & $0.86^{* * *}$ & $0.81^{* * *}$ & $0.61 * * *$ & 0.61 \\
\hline More than two earners & $\begin{array}{l}(0.03) \\
0.88 * * * \\
(0.07)\end{array}$ & $\begin{array}{l}(0.01) \\
0.85 * * * \\
(0.02)\end{array}$ & $\begin{array}{l}(0.05) \\
0.69 * * * \\
(0.05)\end{array}$ & 0.63 \\
\hline
\end{tabular}

Notes: See notes to Table 3. Columns 1 and 2 are private insurance participation rates when a Medicaid eligible child stays eligible, ignoring unobservables. Column 3 presents private insurance participation rates when a Medicaid eligible child stays eligible, including the effect of unobservables. Estimates in columns (2) and (3) are based on maximizing (11). 
Table 6: Estimated Crowd-out Rates for All Eligible Children

\begin{tabular}{|c|c|c|c|}
\hline Group & $\begin{array}{l}\text { LPMI } \\
\text { (1) }\end{array}$ & $\begin{array}{l}\text { SPM - Unobservables } \\
\text { Ignored } \\
\text { (2) }\end{array}$ & $\begin{array}{l}\text { SPM - Unobservables } \\
\text { Accounted for } \\
\text { (3) }\end{array}$ \\
\hline All Population & $\begin{array}{l}-0.05^{* *} \\
(0.02)\end{array}$ & $\begin{array}{l}-0.02 * \\
(0.01)\end{array}$ & $\begin{array}{l}-0.05 \\
(0.03)\end{array}$ \\
\hline \multicolumn{4}{|l|}{ Race } \\
\hline White & $\begin{array}{l}-0.05^{* *} \\
(0.02)\end{array}$ & $\begin{array}{l}-0.01 \\
(0.01)\end{array}$ & $\begin{array}{l}-0.05 \\
(0.04)\end{array}$ \\
\hline Non-White & $\begin{array}{l}-0.06^{*} \\
(0.04)\end{array}$ & $\begin{array}{l}-0.02^{*} \\
(0.01)\end{array}$ & $\begin{array}{l}-0.04 \\
(0.03)\end{array}$ \\
\hline \multicolumn{4}{|c|}{ Education of Highest Earner } \\
\hline High School Drop-out & $\begin{array}{l}-0.08^{* *} \\
(0.03)\end{array}$ & $\begin{array}{l}-0.005 \\
(0.01)\end{array}$ & $\begin{array}{l}-0.02 \\
(0.03)\end{array}$ \\
\hline High School Graduate & $\begin{array}{l}-0.05^{* *} \\
(0.02)\end{array}$ & $\begin{array}{l}-0.03^{* * * *} \\
(0.01)\end{array}$ & $\begin{array}{l}-0.06 \\
(0.04)\end{array}$ \\
\hline Some College & $\begin{array}{l}-0.03 \\
(0.02)\end{array}$ & $\begin{array}{l}-0.04^{* * *} \\
(0.01)\end{array}$ & $\begin{array}{l}-0.07 \\
(0.04)\end{array}$ \\
\hline College Graduate & $\begin{array}{c}0.03 \\
(0.08)\end{array}$ & $\begin{array}{l}-0.02 \\
(0.02)\end{array}$ & $\begin{array}{l}-0.06 \\
(0.05)\end{array}$ \\
\hline \multicolumn{4}{|l|}{ Family Structure } \\
\hline Female Head & $\begin{array}{l}-0.10^{* *} \\
(0.04)\end{array}$ & $\begin{array}{l}-0.04^{* * *} \\
(0.01)\end{array}$ & $\begin{array}{l}-0.05 * * \\
(0.03)\end{array}$ \\
\hline Male Head & $\begin{array}{l}-0.16^{* *} \\
(0.04)\end{array}$ & $\begin{array}{l}-0.03 \\
(0.02)\end{array}$ & $\begin{array}{l}-0.06 \\
(0.05)\end{array}$ \\
\hline Two parents & $\begin{array}{l}-0.005 \\
(0.02)\end{array}$ & $\begin{array}{l}-0.004 \\
(0.01)\end{array}$ & $\begin{array}{l}-0.04 \\
(0.04)\end{array}$ \\
\hline \multicolumn{4}{|l|}{ Number of Earners } \\
\hline No earner & $\begin{array}{l}-0.11^{* *} \\
(0.05)\end{array}$ & $\begin{array}{l}-0.03^{*} \\
(0.01)\end{array}$ & $\begin{array}{l}-0.03 \\
(0.02)\end{array}$ \\
\hline One earner & $\begin{array}{l}-0.03^{* *} \\
(0.02)\end{array}$ & $\begin{array}{l}-0.03^{*} \\
(0.01)\end{array}$ & $\begin{array}{l}-0.06 \\
(0.05)\end{array}$ \\
\hline Two earners & $\begin{array}{l}0.08^{* *} \\
(0.04)\end{array}$ & $\begin{array}{c}0.002 \\
(0.01)\end{array}$ & $\begin{array}{l}-0.04 \\
(0.05)\end{array}$ \\
\hline More than two earners & $\begin{array}{c}0.10 \\
(0.07)\end{array}$ & $\begin{array}{c}0.03 \\
(0.02)\end{array}$ & $\begin{array}{c}0.01 \\
(0.06)\end{array}$ \\
\hline
\end{tabular}

Notes: See notes to Table 3. Estimates are based on coefficients estimated using data from all SIPP panels and Medicaid eligible children in the 1995 data. Recall that the SPM estimates separate private insurance participation equations when eligible for Medicaid and when ineligible. Thus, estimates in Columns (2) and (3) are calculated using coefficients from Columns (3) and (4) of Table B2 in the Online Appendix, respectively. 
Table 7: Counterfactual Policy Analysis: Estimated Private Insurance Coverage Rates for the Newly Eligible after Raising the Income Limits by $10 \%$

\begin{tabular}{|c|c|c|c|}
\hline Group & $\begin{array}{l}\text { LPMI } \\
(1)\end{array}$ & $\begin{array}{c}\text { SPM - Unobservables } \\
\text { Ignored } \\
\text { (2) }\end{array}$ & $\begin{array}{c}\text { SPM - Unobservables } \\
\text { Accounted For } \\
\text { (3) }\end{array}$ \\
\hline All Newly Eligible Population & $\begin{array}{l}0.74^{* * * *} \\
(0.03)\end{array}$ & $\begin{array}{l}0.71 * * * \\
(0.01)\end{array}$ & $\begin{array}{l}0.49 * * * \\
(0.05)\end{array}$ \\
\hline Race & & & \\
\hline White & $\begin{array}{l}0.76^{* * * *} \\
(0.03)\end{array}$ & $\begin{array}{l}0.73 * * * \\
(0.01)\end{array}$ & $\begin{array}{l}0.52 * * * \\
(0.05)\end{array}$ \\
\hline Non-White & $\begin{array}{l}0.65^{* * * *} \\
(0.03)\end{array}$ & $\begin{array}{l}0.62^{* * * *} \\
(0.01)\end{array}$ & $\begin{array}{l}0.39 * * * \\
(0.05)\end{array}$ \\
\hline Education of Highest Earner & & & \\
\hline High School Drop-out & $\begin{array}{l}0.57 * * * \\
(0.03)\end{array}$ & $\begin{array}{l}0.55^{* * *} \\
(0.01)\end{array}$ & $\begin{array}{l}0.33 * * * \\
(0.04)\end{array}$ \\
\hline High School Graduate & $\begin{array}{l}0.74 * * * \\
(0.03)\end{array}$ & $\begin{array}{l}0.72 * * * \\
(0.01)\end{array}$ & $\begin{array}{l}0.51 * * * \\
(0.05)\end{array}$ \\
\hline Some College & $\begin{array}{l}0.78 * * * \\
(0.03)\end{array}$ & $\begin{array}{l}0.76^{* * *} \\
(0.01)\end{array}$ & $\begin{array}{l}0.54^{* * *} \\
(0.05)\end{array}$ \\
\hline College Graduate & $\begin{array}{l}0.99 * * * \\
(0.04)\end{array}$ & $\begin{array}{l}0.90^{* * * *} \\
(0.01)\end{array}$ & $\begin{array}{l}0.70^{* * * *} \\
(0.05)\end{array}$ \\
\hline Family Structure & & & \\
\hline Female Head & $\begin{array}{l}0.59 * * * \\
(0.03)\end{array}$ & $\begin{array}{l}0.58 * * * \\
(0.01)\end{array}$ & $\begin{array}{l}0.37 * * * \\
(0.04)\end{array}$ \\
\hline Male Head & $\begin{array}{l}0.62 * * * \\
(0.05)\end{array}$ & $\begin{array}{l}0.67 * * * \\
(0.02)\end{array}$ & $\begin{array}{l}0.42^{* * *} \\
(0.05)\end{array}$ \\
\hline Two parents & $\begin{array}{l}0.80 * * * \\
(0.03)\end{array}$ & $\begin{array}{l}0.76^{* * * *} \\
(0.01)\end{array}$ & $\begin{array}{l}0.55^{* * * *} \\
(0.05)\end{array}$ \\
\hline Number of Earners & & & \\
\hline No earner & $\begin{array}{l}0.24^{* * *} \\
(0.03)\end{array}$ & $\begin{array}{l}0.23 * * * \\
(0.01)\end{array}$ & $\begin{array}{l}0.16^{* * * *} \\
(0.02)\end{array}$ \\
\hline One earner & $\begin{array}{l}0.71 * * * \\
(0.03)\end{array}$ & $\begin{array}{l}0.69 * * * \\
(0.01)\end{array}$ & $\begin{array}{l}0.47 * * * \\
(0.05)\end{array}$ \\
\hline Two earners & $\begin{array}{l}090 * * * \\
(0.04)\end{array}$ & $\begin{array}{l}0.84 * * * \\
(0.01)\end{array}$ & $\begin{array}{l}0.60 * * * \\
(0.05)\end{array}$ \\
\hline More than two earners & $\begin{array}{l}0.99 * * * \\
(0.01)\end{array}$ & $\begin{array}{l}0.93 * * * \\
(0.02)\end{array}$ & $\begin{array}{l}0.72 * * * \\
(0.06)\end{array}$ \\
\hline
\end{tabular}

Notes: See notes to Table 3. Estimates are based on parameter estimates for the entire sample and the characteristics of the children in the 1995 SIPP data made newly eligible for Medicaid under our counterfactual policy experiment of raising the 1995 Medicaid income eligibility limits by $10 \%$. 
Table 8: Counterfactual Policy Analysis: Crowd-out Rates for the Newly Eligible Population after Raising Medicaid Income Limits by $\mathbf{1 0 \%}$

\begin{tabular}{|c|c|c|c|}
\hline Group & $\begin{array}{l}\text { LPMI } \\
\text { (1) }\end{array}$ & $\begin{array}{l}\text { SPM - Unobservables } \\
\text { Ignored } \\
\text { (2) }\end{array}$ & $\begin{array}{l}\text { SPM - Unobservables } \\
\text { Accounted for } \\
\text { (3) }\end{array}$ \\
\hline All Population & $\begin{array}{l}-0.03 \\
(0.05)\end{array}$ & $\begin{array}{l}-0.02 \\
(0.01)\end{array}$ & $\begin{array}{l}-0.07 \\
(0.06)\end{array}$ \\
\hline \multicolumn{4}{|l|}{ Race } \\
\hline White & $\begin{array}{c}0.03 \\
(0.05)\end{array}$ & $\begin{array}{l}-0.02 \\
(0.01)\end{array}$ & $\begin{array}{l}-0.07 \\
(0.06)\end{array}$ \\
\hline Non-White & $\begin{array}{c}0.04 \\
(0.05)\end{array}$ & $\begin{array}{l}-0.01 \\
(0.02)\end{array}$ & $\begin{array}{l}-0.06 \\
(0.06)\end{array}$ \\
\hline \multicolumn{4}{|c|}{ Education of Highest Earner } \\
\hline High School Drop-out & $\begin{array}{c}0.02 \\
(0.05)\end{array}$ & $\begin{array}{c}0.02 \\
(0.02)\end{array}$ & $\begin{array}{l}-0.01 \\
(0.05)\end{array}$ \\
\hline High School Graduate & $\begin{array}{c}0.02 \\
(0.05)\end{array}$ & $\begin{array}{l}-0.03^{*} \\
(0.02)\end{array}$ & $\begin{array}{l}-0.07 \\
(0.06)\end{array}$ \\
\hline Some College & $\begin{array}{c}0.03 \\
(0.05)\end{array}$ & $\begin{array}{l}-0.03^{* *} \\
(0.01)\end{array}$ & $\begin{array}{l}-0.09 \\
(0.06)\end{array}$ \\
\hline College Graduate & $\begin{array}{c}0.10 \\
(0.05)\end{array}$ & $\begin{array}{l}-0.02 \\
(0.01)\end{array}$ & $\begin{array}{l}-0.09 \\
(0.06)\end{array}$ \\
\hline \multicolumn{4}{|l|}{ Family Structure } \\
\hline Female Head & $\begin{array}{l}-0.01 \\
(0.05)\end{array}$ & $\begin{array}{l}-0.03^{*} \\
(0.02)\end{array}$ & $\begin{array}{l}-0.09 \\
(0.05)\end{array}$ \\
\hline Male Head & $\begin{array}{l}-0.10 \\
(0.07)\end{array}$ & $\begin{array}{l}-0.02 \\
(0.03)\end{array}$ & $\begin{array}{l}-0.07 \\
(0.07)\end{array}$ \\
\hline Two parents & $\begin{array}{c}0.06 \\
(0.05)\end{array}$ & $\begin{array}{l}-0.01 \\
(0.01)\end{array}$ & $\begin{array}{l}-0.06 \\
(0.06)\end{array}$ \\
\hline \multicolumn{4}{|l|}{ Number of Earners } \\
\hline No earner & $\begin{array}{l}-0.01 \\
(0.07)\end{array}$ & $\begin{array}{l}-0.00 \\
(0.02)\end{array}$ & $\begin{array}{l}-0.02 \\
(0.03)\end{array}$ \\
\hline One earner & $\begin{array}{c}0.01 \\
(0.05)\end{array}$ & $\begin{array}{l}-0.03^{*} \\
(0.01)\end{array}$ & $\begin{array}{l}-0.08 \\
(0.06)\end{array}$ \\
\hline Two earners & $\begin{array}{c}0.09 \\
(0.06)\end{array}$ & $\begin{array}{l}-0.01 \\
(0.01)\end{array}$ & $\begin{array}{l}-0.06 \\
(0.06)\end{array}$ \\
\hline More than two earners & $\begin{array}{c}0.13 \\
(0.09)\end{array}$ & $\begin{array}{c}0.01 \\
(0.02)\end{array}$ & $\begin{array}{l}-0.03 \\
(0.07)\end{array}$ \\
\hline
\end{tabular}

Notes: See notes to Table 3. Estimates are based on coefficients estimated using data from all SIPP panels and children in the 1995 data made newly eligible by the increase in the Medicaid income limits. Estimates in Columns (2) and (3) are calculated using coefficients from Columns (3) and (4) of Table B2 in the Online Appendix, respectively. 